\title{
A DFT study of reversed isotope shifts in H/D substitution of free-base porphyrin and related free-base tetrapyrroles
}

\author{
Christopher Henchy, Ciaran Murray, Claudine Crépin, and John G. McCaffrey
}

\begin{abstract}
DFT/B3LYP calculations are used to analyse the occurrence of reverse isotope shift ratios (ISR) in H/D substitution of the free-base tetrapyrroles, in situations where the frequency ratio $\nu_{\mathrm{H}} / \nu_{\mathrm{D}}$ is less than 1 . The reverse ISR effect is found to be most evident in the out-of-plane bending modes $\left(b_{2 g}\right.$ and $b_{3 u}$ symmetry) involving some $\mathrm{N}-\mathrm{H}$ motion for the four molecules studied, viz., porphine $\left(\mathrm{H}_{2} \mathrm{P}\right)$, tetraaza-porphine $\left(\mathrm{H}_{2} \mathrm{TAP}\right)$, tetrabenzo-porphine $\left(\mathrm{H}_{2} \mathrm{TBP}\right)$, and phthalocyanine $\left(\mathrm{H}_{2} \mathrm{Pc}\right)$. It was analysed by following the evolution of the normal mode frequencies with incremental variation of the $\mathrm{H}$ atom masses from 1 to $2 \mathrm{amu}$. This method allows direct, unambiguous mode correlations to be established between the light and the heavy isotopologues. When the $\mathrm{NH}(\mathrm{D})$ motion is predominant, the $\mathrm{H}$ to $\mathrm{D}$ frequency evolution decreases in a continuous manner for a particular normal mode. In the case of two modes of the same symmetry and whose frequencies are similar, their frequency evolutions could cross, depending on the extent of NH(D) motion involved in them. The evolution diagrams may show avoided crossings of various extents, which thereby reflects the degree of the NH(D) motion in the modes. The reverse ISR effect is directly correlated to these avoided crossings. Because the isotope shifts are quite small $\left(<10 \mathrm{~cm}^{-1}\right)$ and occur in the congested $1500-500 \mathrm{~cm}^{-1}$ spectral region, high-resolution methods yielding narrow line transitions are required for experimental analysis. The matrix isolation technique is particularly well suited for this work and is proposed for use in a search for this effect.
\end{abstract}

Key words: vibrational spectroscopy, porphyrins, DFT calculations, matrix-isolation.

Résumé : Des calculs DFT basés sur la fonctionnelle B3LYP ont été menés sur des molécules tétrapyrroliques afin d'analyser le cas de rapports de déplacements isotopiques (RDI) inverses reliés à la substitution H/D dans les bases libres, c'est-à-dire le cas de rapports de fréquences $\nu_{\mathrm{H}} / \nu_{\mathrm{D}}$ inférieurs à 1 . Ces rapports RDI inverses apparaissent clairement dans les modes de pliage hors plan (symétries $b_{2 g}$ et $b_{3 u}$ ) impliquant un mouvement $\mathrm{N}-\mathrm{H}$ pour les quatre molécules étudiées : porphine $\left(\mathrm{H}_{2} \mathrm{P}\right)$, tétraazaporphine $\left(\mathrm{H}_{2} \mathrm{TAP}\right)$, tétrabenzoporphine $\left(\mathrm{H}_{2} \mathrm{TBP}\right)$ et phthalocyanine $\left(\mathrm{H}_{2} \mathrm{Pc}\right)$. Les $\mathrm{RDI}$ inverses ont été analysés en suivant l'évolution des fréquences des modes normaux lors d'une augmentation continue de 1 à 2 amu de la masse de l'atome d'hydrogène. Cette méthode permet d'établir de façon directe et non ambiguë les corrélations entre les fréquences des deux isotopologues. Lorsque le mouvement $\mathrm{N}-\mathrm{H}(\mathrm{D})$ est prédominant dans un mode donné, l'évolution de la fréquence de $\mathrm{H}$ à $\mathrm{D}$ diminue continûment. Lorsque deux modes de même symétrie ont des fréquences voisines, leurs évolutions en fréquence de $\mathrm{H}$ à $\mathrm{D}$ peuvent se croiser, selon le degré d'implication du mouvement N-H(D) dans les deux modes considérés. Les diagrammes d'évolutions correspondants peuvent alors montrer des croisements évités plus ou moins prononcés, reflétant ainsi le poids du mouvement N-H(D) dans les modes impliqués. L'effet de RDI inversé est directement corrélé à ces croisements évités. Les déplacements isotopiques sont assez faibles $\left(<10 \mathrm{~cm}^{-1}\right)$ et ont lieu dans une région spectrale très dense $\left(1500-500 \mathrm{~cm}^{-1}\right)$. C'est pourquoi, il est nécessaire d'utiliser des méthodes spectroscopiques à haute résolution permettant l'observation de transitions en bandes fines pour une analyse expérimentale. La technique d'isolation en matrice est particulièrement bien adaptée et elle est proposée pour la recherche expérimentale de cet effet.

Mots-clés : spectroscopie vibrationnelle, porphyrines, calculs DFT, isolation en matrice.

Received 11 July 2012. Accepted 10 September 2012. Published at www.nrcresearchpress.com/cjc on 27 November 2012.

C. Henchy, C. Murray*, and J.G. McCaffrey. Department of Chemistry, National University of Ireland, Maynooth, Co. Kildare, Ireland.

C. Crépin. Institut des Sciences Moléculaires d'Orsay - UMR 8214 (ISMO), Bâtiment 210, Université Paris-Sud, 91405 Orsay CEDEX, France.

Corresponding author: John G. McCaffrey (e-mail: john.mccaffrey@nuim.ie).

*Present address: Tyndall National Institute, Lee Maltings, University College, Cork, Ireland.

The time one of us $(\mathrm{JMcC})$ spent as a graduate student in Geff Ozin's group was the beginning of an enriching, life-long career in research and education. In particular, the use of group theoretical quantum chemistry and the matrix-isolation techniques, all of which are used in this contribution, were first encountered in the Ozin lab. Accordingly, it is with pleasure and gratitude that the present article is dedicated to Geff. 


\section{Introduction}

The tautomerism exhibited by the free-base tetrapyrroles, in which the two inner hydrogen atoms migrate between opposite pairs of the four central nitrogen atoms, has been studied with a wide variety of both experimental ${ }^{1}$ and theoretical ${ }^{2}$ means. Of the methods applied, vibrational spectroscopy is a direct means of probing the mechanism underlying the tautomerism, since the $\mathrm{N}-\mathrm{H}$ stretch and in-plane bending modes have been proposed to be involved. In spectroscopic work, isotope substitution $^{3}$ is a well-known tool in achieving a reliable vibrational analysis, with substitution of hydrogen $(\mathrm{H})$ by deuterium (D) by far the most utilized method, as it produces the largest frequency shifts ${ }^{4}$ because of the approximate factor of two ${ }^{5}$ difference in the masses of the isotopes. Arising from the inverse relationship between the mode frequency, $\nu$, and the mass of the $\mathrm{H}$-atom isotope, $m$, given by the expression,

$$
v=\frac{1}{2 \pi} \sqrt{\frac{k}{m}}
$$

in which $k$ is the force constant, the heavier isotope is thereby expected to occur at lower values. This behaviour assists greatly in making mode assignments in experimental spectra. Moreover, for the free-base tetrapyrroles, H/D substitution of the two inner hydrogens is particularly appealing as the $D_{2 h}$ molecular symmetry is conserved, allowing direct comparisons between the two isotopologues.

However, in a recent combined IR/Raman and high-level density functional theory (DFT) study ${ }^{6}$ of free-base phthalocyanine $\left(\mathrm{H}_{2} \mathrm{Pc}\right)$, we observed quite peculiar behaviour upon H/D substitution, whereby the frequency of one particular mode of the deuterium isotopologue was found to be higher than that of hydrogen. The mode in question is the IR-active out-of-plane bending vibration observed in Ar matrices at $722.7 \mathrm{~cm}^{-1}$ for $\mathrm{H}_{2} \mathrm{Pc}$, but which shifts up to $729.9 \mathrm{~cm}^{-1}$ in $\mathrm{D}_{2} \mathrm{Pc}$. The observed isotope shift ratio (ISR) of 0.990 , determined as the $\nu_{\mathrm{H}} / \nu_{\mathrm{D}}$ ratio, was very well reproduced in the theoretical DFT results. To probe whether this unusual reversed ISR $(<1)$ effect is a peculiarity of Pc, we have extended the theoretical work in the present study to cover the 3 most closely related free-base tetrapyrroles, namely porphine (P), tetraaza-porphine (TAP), and tetrabenzo-porphine (TBP). The structures of all four molecules are provided in Fig. 1, revealing the strong similarities of these very important materials, often called the "colours of life". 7

A theoretical prediction of the occurrence of a reversed isotope shift ratio (ISR $<1$ ) was made several years ago by $\mathrm{Li}$ and Zgierski in their work on developing a local mode description of the vibrations in the porphines for both free-base and metallo-porphines. ${ }^{8}$ Their vibrational analysis was based on a valence force field and conducted with the Wilson-GF matrix method. ${ }^{9}$ However, as will be shown later, the upward shifts in the heavier isotope were much larger than what we have seen with the force fields generated in the present quantum chemical method. The earlier work ${ }^{8}$ only considered in-plane vibrations, i.e., the $\mathrm{N}-\mathrm{H}$ stretches and in-plane bending modes, but as we have found experimentally ${ }^{6}$, the most easily identifiable instance of the reversed ISR effect in the phthalocyanines involved an out-of-plane $\mathrm{N}-\mathrm{H}$ bending
Fig. 1. Structures of the 4 closely related free-base tetrapyrrole molecules, namely porphine $\left(\mathrm{H}_{2} \mathrm{P}\right)$, tetraaza-porphine $\left(\mathrm{H}_{2} \mathrm{TAP}\right)$, tetrabenzo-porphine $\left(\mathrm{H}_{2} \mathrm{TBP}\right)$ and phthalocyanine $\left(\mathrm{H}_{2} \mathrm{Pc}\right)$, whose vibrational frequency shifts upon H/D isotope substitution have been studied by the DFT method. The bond lengths and bond angles found in the DFT/B3LYP geometry optimisations are provided in Table 2 for the four molecules. With the present method, all are found to have high $\left(D_{2 h}\right)$ symmetry.<smiles></smiles>

$\mathrm{H}_{2} \mathrm{P}$

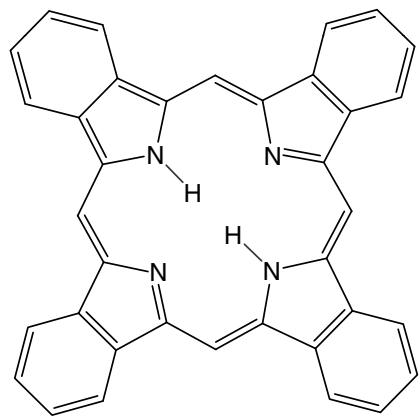

$\mathrm{H}_{2} \mathrm{TBP}$

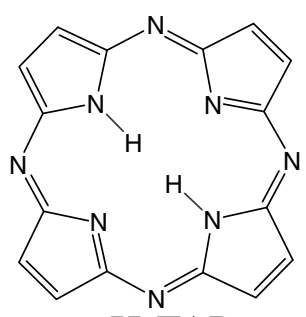

$\mathrm{H}_{2}$ TAP

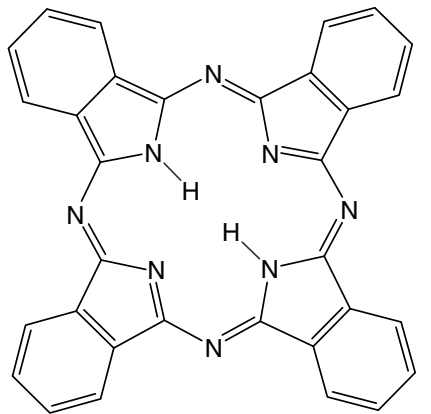

$\mathrm{H}_{2} \mathrm{Pc}$ motion. A more recent DFT calculation of free-base phthalocyanine by Liu et al. also found a reverse ISR. ${ }^{10}$ While these authors did not present an analysis of the origins of this effect, they did comment that for the mode concerned, the direction of the $\mathrm{H}$ atom motions was opposite to that of the $\mathrm{D}$ atoms.

A group theoretical analysis of the four free-base tetrapyrroles, all belonging to the $D_{2 h}$ point group, provides the symmetry types and numbers of the normal vibrational modes of the molecules being studied. The results of such an analysis, in which the $z$-axis is aligned with the two central $\mathrm{N}-\mathrm{H}$ bonds, are collected in Table 1. ${ }^{11}$ As expected, the numbers of modes in the two tetra-aryl molecules (tetrabenzo-porphine and phthalocyanine) are much larger because of the increase in the number of atoms, N. For the purposes of illustration, the material presented herein will concentrate on the smaller parent molecules porphine and tetraaza-porphine. However, in all four molecules the symmetry types of the 6 modes involving $\mathrm{N}-\mathrm{H}$ motion are the same and can be compared with the complete normal vibrational modes in Table 1 .

The main goal then is to establish the correlations between similar NH and ND modes and to rationalize the observed and calculated frequency shifts. Calculating normal mode frequencies with incremental (artificial) variation of the masses of $\mathrm{H}$ from 1 to 2 allows these correlations to be established. When the $\mathrm{NH}(\mathrm{D})$ motion is predominant, the $\mathrm{H}$ to $\mathrm{D}$ evolution in the normal mode frequency will decrease in a continuous manner. In the case of two modes of the same symmetry and whose 
Table 1. A summary of a group theoretical analysis of the normal modes of vibration for the tetra-pyrrole molecules examined in the present work.

\begin{tabular}{|c|c|c|c|c|c|c|c|}
\hline \multirow{2}{*}{$\begin{array}{l}D_{2 h} \\
\text { Sym. }\end{array}$} & \multicolumn{4}{|l|}{ Species } & \multicolumn{3}{|c|}{$\begin{array}{l}\mathrm{N}-\mathrm{H} \\
\text { vibrational } \\
\text { modes }\end{array}$} \\
\hline & $\mathrm{H}_{2} \mathrm{P}(38)$ & $\mathrm{H}_{2} \mathrm{TAP}(34)$ & $\mathrm{H}_{2} \mathrm{TBP}(62)$ & $\mathrm{H}_{2} \mathrm{Pc}(58)$ & STR & IPB & OPB \\
\hline$\overline{a_{g}}$ & 19 & 17 & 31 & 29 & $\checkmark$ & & \\
\hline$b_{1 g}$ & 8 & 7 & 14 & 13 & & & \\
\hline$b_{2 g}$ & 9 & 8 & 15 & 14 & & & $\checkmark$ \\
\hline$b_{3 g}$ & 18 & 16 & 30 & 28 & & $\checkmark$ & \\
\hline$a_{u}$ & 8 & 7 & 14 & 13 & & & \\
\hline$b_{1 u}$ & 18 & 16 & 30 & 28 & $\checkmark$ & & \\
\hline$b_{2 u}$ & 18 & 16 & 30 & 28 & & $\checkmark$ & \\
\hline$b_{3 u}$ & 10 & 9 & 16 & 15 & & & $\checkmark$ \\
\hline \#Modes & 108 & 96 & 180 & 168 & & & \\
\hline
\end{tabular}

Note: The values in parenthesis are the numbers of atoms in each of the molecules. On the right-hand side, the symmetries of the six possible $\mathrm{N}-\mathrm{H}$ motions are provided for an analysis conducted with the $z$-axis co-linear with the two central N-H bonds. The abbreviations STR, IPB, and OPB represent the N-H stretching, in-plane bending, and out-of-plane bending modes, respectively.

frequencies are similar, their frequency evolutions could cross, depending on the extent of $\mathrm{NH}(\mathrm{D})$ motion involved in them. The evolution diagrams will thus show avoided crossings of various extents, which thereby reveal the degree of the NH(D) motion in the modes. If both normal modes involve similar atomic motions, including the $\mathrm{NH}(\mathrm{D})$ one, they will be distorted around the mass of $\mathrm{H}$ corresponding to the crossing, to avoid it. This is similar to the well-known characteristic of avoided crossing found in potential energy surfaces for electronic states with the same spatial symmetry. ${ }^{12}$ It allows an analysis of the underlying mode interactions. In the present paper, the instances of ISR $<1$ are especially focussed on.

\section{Methods}

DFT was utilized with the $6-311 \mathrm{G}++(2 \mathrm{~d}, 2 \mathrm{p})$ basis set for both geometry optimization and the calculation of the vibrational frequencies. The B3LYP functional is currently the most effective for calculating ground-state molecular vibrational frequencies, and when used with a large basis set, generates accurate IR intensities. Moreover, as demonstrated in our previous study of both zinc and free-base phthalocyanine, the Raman intensities are also reliable. ${ }^{6}$ Another advantage of this method is that it runs efficiently on multiprocessor computers. The present calculations were conducted with the Gaussian-03 suite of programmes $^{13}$ running, as described elsewhere ${ }^{6}$, on a Linux workstation with two quad-core processors. All the calculated vibrational frequencies presented in this work are, unless stated otherwise, unscaled values obtained within the harmonic approximation.

Because of the un-intuitive nature of the effect being analysed, the approach taken in calculating the vibrational frequencies involves increasing the masses between $\mathrm{H}$ and $\mathrm{D}$ incrementally, in steps of $0.05 \mathrm{amu}$, so that the evolution of the modes from the light to the heavy isotopologue can be followed in a near-continuous manner. This is the approach we utilized in our previous phthalocyanine work. ${ }^{6}$ Recently, this method has been applied successfully by Wright and coworkers in their work on re-numbering the vibrational modes of benzene and its monosubstituted derivatives. ${ }^{14}$ The task in the present analysis is to track the mass dependence of the normal modes to see where they cross, but more importantly, it is to identify where curve-avoidance occurs and analyse the underlying mode coupling that produce ISR values less than 1 . In doing this, we exploit the high symmetries found in the optimized geometries of the free-base tetrapyrroles. Accordingly, this analysis is done on normal modes of a given symmetry type with a particular focus on those modes involving the $\mathrm{N}-\mathrm{H}$ vibrations. As mentioned earlier, there are only 3 types of N-H motions, but 6 distinct symmetries are involved. Thus, the reducible representation $(\Gamma)$ for motion involving ONLY the two inner H-atoms (iH) can be shown to be $\Gamma_{i H}=$ $6-2000022$. Application of the reduction formula to $\Gamma_{\mathrm{iH}}$ gives the symmetries of the $\mathrm{N}-\mathrm{H}$ vibrations as $1 a_{g}, 1 b_{2 g}, 1 b_{3 g}$, $1 b_{1 u}, 1 b_{2 u}$, and $1 b_{3 u}$. These 6 modes as listed in Table 1 for the 4 free-base molecules considered.

To analyse details of the atomic motions producing the reverse isotope substitution ratios (ISR $<1$ ), we have extracted the contributions of the internal coordinates to the normal modes. The internal mode contributions to a specific normal mode are expressed as percentages, which were generated directly in the Gaussian-03 package. ${ }^{15}$ The calculation of the "\% Internal modes" involves a projection of the normal modes onto the displacement vectors that define the redundant internal coordinates. Only the most important terms are given, with the default being all modes greater than 0.1 , with the cut-off being reduced until the total of 0.9 is reached. This is implemented with the "freq=internal" command in the input file.

\section{Results}

The optimized geometries obtained with the DFT/B3LYP method and the $6-311 \mathrm{G}++(2 \mathrm{~d}, 2 \mathrm{p})$ basis set for the 4 freebase tetrapyrrole molecules studied are shown in Fig. 1. Complete listings of the geometric parameters for the free-base tetrapyrroles, porphine $\left(\mathrm{H}_{2} \mathrm{P}\right)$, tetraaza-porphine $\left(\mathrm{H}_{2} \mathrm{TAP}\right)$, tetrabenzo-porphine $\left(\mathrm{H}_{2} \mathrm{TBP}\right)$, and phthalocyanine $\left(\mathrm{H}_{2} \mathrm{Pc}\right)$ are provided in Table 2 . In all cases, high $\left(D_{2 h}\right)$ symmetry was preserved in the geometry optimisations, and no imaginary 
Table 2. A summary of the geometric parameters obtained with the DFT/B3LYP optimization conducted in the present work on the 4 free-base tetrapyrrole molecules, porphine $\left(\mathrm{H}_{2} \mathrm{P}\right)$, tetraaza-porphine $\left(\mathrm{H}_{2} \mathrm{TAP}\right)$, tetrabenzo-porphine $\left(\mathrm{H}_{2} \mathrm{TBP}\right)$, and phthalocyanine $\left(\mathrm{H}_{2} \mathrm{Pc}\right)$.

\begin{tabular}{|c|c|c|c|c|}
\hline Length $(\AA)$ & $\mathrm{P}$ & TAP & TBP & $\mathrm{Pc}$ \\
\hline $\mathrm{N}-\mathrm{H}$ & 1.0104 & 1.0076 & 1.0112 & 1.009 \\
\hline $\mathrm{N}-\mathrm{C}_{\alpha}$ & 1.3692 & 1.3701 & 1.3709 & 1.375 \\
\hline $\mathrm{C}_{\alpha}-\mathrm{C}_{\mathrm{m}}$ & 1.3900 & - & 1.3839 & - \\
\hline $\mathrm{C}_{\alpha}-\mathrm{N}_{\mathrm{m}}$ & - & 1.3195 & - & 1.313 \\
\hline $\mathrm{C}_{\alpha}-\mathrm{C}_{\beta}$ & 1.4316 & 1.4436 & 1.4448 & 1.45 \\
\hline $\mathrm{C}_{\beta}-\mathrm{C}_{\beta}$ & 1.368 & 1.3616 & 1.413 & 1.409 \\
\hline $\mathrm{C}_{\beta}-\mathrm{H}_{1}$ & 1.0768 & 1.0759 & - & - \\
\hline $\mathrm{C}_{\beta}-\mathrm{C}_{\gamma}$ & - & - & 1.3985 & 1.394 \\
\hline $\mathrm{C}_{\gamma}-\mathrm{C}_{\delta}$ & - & - & 1.3828 & 1.386 \\
\hline $\mathrm{C}_{\delta}-\mathrm{C}_{\delta}$ & - & - & 1.4073 & 1.406 \\
\hline $\mathrm{C}_{\gamma}-\mathrm{H}_{1}$ & - & - & 1.0812 & 1.08 \\
\hline $\mathrm{C}_{\delta}-\mathrm{H}_{2}$ & - & - & 1.0812 & 1.081 \\
\hline $\mathrm{N}^{\prime}-\mathrm{C}_{\alpha^{\prime}}$ & 1.3600 & 1.3593 & 1.3598 & 1.362 \\
\hline $\mathrm{C}_{\alpha^{\prime}}-\mathrm{C}_{\mathrm{m}}$ & 1.3961 & - & 1.3949 & - \\
\hline $\mathrm{C}_{\alpha^{\prime}}-\mathrm{N}_{\mathrm{m}}$ & - & 1.3338 & - & 1.332 \\
\hline $\mathrm{C}_{\mathrm{m}}-\mathrm{H}_{\mathrm{m}}$ & 1.0812 & - & 1.0806 & - \\
\hline $\mathrm{C}_{\alpha^{\prime}}-\mathrm{C}_{\beta^{\prime}}$ & 1.457 & 1.4657 & 1.4632 & 1.465 \\
\hline $\mathrm{C}_{\beta^{\prime}}-\mathrm{C}_{\beta^{\prime}}$ & 1.3521 & 1.3466 & 1.404 & 1.4 \\
\hline $\mathrm{C}_{\beta^{\prime}}-\mathrm{H}_{1^{\prime}}$ & 1.078 & 1.0766 & - & - \\
\hline $\mathrm{C}_{\beta^{\prime}}-\mathrm{C}_{\gamma^{\prime}}$ & - & - & 1.3931 & 1.389 \\
\hline $\mathrm{C}_{\gamma^{\prime}}-\mathrm{C}_{\delta^{\prime}}$ & - & - & 1.3894 & 1.392 \\
\hline $\mathrm{C}_{\delta^{\prime}}-\mathrm{C}_{\delta^{\prime}}$ & - & - & 1.4014 & 1.401 \\
\hline $\mathrm{C}_{\gamma^{\prime}}-\mathrm{H}_{1^{\prime}}$ & - & - & 1.0818 & 1.081 \\
\hline $\mathrm{C}_{\delta^{\prime}}-\mathrm{H}_{2^{\prime}}$ & - & - & 1.0814 & 1.081 \\
\hline
\end{tabular}

Angle $\left({ }^{\circ}\right)$

$\mathrm{H}-\mathrm{N}-\mathrm{C}_{\alpha}$

$\mathrm{N}-\mathrm{C}_{\alpha}-\mathrm{C}_{\mathrm{m}}$

124.5724

124.5932

123.6462

126.1288

$\mathrm{N}-\mathrm{C}_{\alpha}-\mathrm{N}_{\mathrm{m}}$

$\mathrm{C}_{\alpha}-\mathrm{N}-\mathrm{C}_{\alpha}$

$\mathrm{N}-\mathrm{C}_{\alpha}-\mathrm{C}_{\beta}$

125.652

110.8552

106.5301

$\mathrm{C}_{\alpha}-\mathrm{C}_{\beta}-\mathrm{C}_{\beta}$

108.0423

124.3741

$\mathrm{C}_{\beta}-\mathrm{C}_{\beta}-\mathrm{H}_{1}$

127.5835

$\mathrm{C}_{\beta}-\mathrm{C}_{\beta}-\mathrm{C}_{\gamma}$

$\mathrm{C}_{\beta}-\mathrm{C}_{\gamma}-\mathrm{C}_{\delta}$

$\mathrm{C}_{\gamma}-\mathrm{C}_{\delta}-\mathrm{C}_{\delta}$

$\mathrm{C}_{\beta}-\mathrm{C}_{\gamma}-\mathrm{H}_{1}$

$\mathrm{C}_{\gamma}-\mathrm{C}_{\delta}-\mathrm{H}_{2}$

$\mathrm{C}_{\alpha}-\mathrm{C}_{\mathrm{m}}-\mathrm{H}_{\mathrm{m}}$

$\mathrm{C}_{\mathrm{\alpha}},-\mathrm{C}_{\mathrm{m}}-\mathrm{H}_{\mathrm{m}}$

$\mathrm{N}^{\prime}-\mathrm{C}_{\alpha^{\prime}}-\mathrm{C}_{\mathrm{m}}$

$\mathrm{N}^{\prime}-\mathrm{C}_{\alpha^{\prime}}-\mathrm{N}_{\mathrm{m}}$

$\mathrm{C}_{\alpha^{\prime}}-\mathrm{N}^{\prime}-\mathrm{C}_{\alpha^{\prime}}$

-

$-$

-

-

- 115.9102

116.9554

125.5188

-

105.7553

110.8457

106.2767

$\mathrm{C}_{\alpha^{\prime}}-\mathrm{C}_{\beta^{\prime}}-\mathrm{C}_{\beta^{\prime}}$

106.2767
125.4496

$\mathrm{C}_{\beta^{\prime}}-\mathrm{C}_{\beta^{\prime}}-\mathrm{H}_{1}$

128.2737

$\mathrm{C}_{\beta^{\prime}}-\mathrm{C}_{\beta^{\prime}}-\mathrm{H}_{2}$

-

$\mathrm{C}_{\beta^{\prime}}-\mathrm{C}_{\beta^{\prime}}-\mathrm{C}_{\gamma^{\prime}}$

-

-

$\mathrm{C}_{\gamma^{\prime}}-\mathrm{C}_{\delta^{\prime}}-\mathrm{C}_{\delta^{\prime}}$

$\mathrm{C}_{\gamma^{\prime}}-\mathrm{C}_{\delta^{\prime}}, \mathrm{H}_{2}$

$-$
127.7457

110.8136

106.5535

108.0397

123.3376

128.6226

-

-

-

-

-

$-$

$-$

-

127.5626

105.5281

111.0377

106.1983

124.2356

129.5661

-

-

-
-

$106.1348-112.527$

$107.5114 \quad 107.601$

-

$-$

$120.5013 \quad 120.960$

$118.4767 \quad 117.829$

$121.022 \quad 121.211$

$121.1432 \quad 120.586$

$119.696 \quad 119.622$

115.3433 -

116.3284

125.6994

121.688

$107.6054 \quad 107.226$

$110.5212 \quad 110.697$

$105.6761 \quad 105.690$

-

120.7253

118.3937

120.8811

121.4854

119.7205 low frequencies were found. These results indicate that the planar geometry is the most stable in all 4 cases.

In the present $\mathrm{H} / \mathrm{D}$ isotope substitution study, we focus on the vibrations involving $\mathrm{N}-\mathrm{H}$ motion of which there are 3 types. As indicated in Table 1, the $\mathrm{N}-\mathrm{H}$ stretching (STR) modes are the $a_{g}$ and $b_{1 u}$ symmetries corresponding to the Raman-active symmetric and IR-active asymmetric vibrations, respectively. The $\mathrm{N}-\mathrm{H}$ in-plane bending (IPB) modes are of $b_{3 g}$ and $b_{2 u}$ symmetry, arising from the in-phase and out-ofphase bending motions, which are Raman-active and IRactive, respectively. The $\mathrm{N}-\mathrm{H}$ out-of-plane bending (OPB) modes are of $b_{2 g}$ and $b_{3 u}$ symmetry, the Raman-active in-phase and IR-active out-of-phase modes, respectively. The behaviour of each of these $3 \mathrm{~N}-\mathrm{H}$ modes will now be analysed on the basis of the 6 possible symmetries that they possess.

From the summary of the group theory results presented in Table 1, one might expect that the H/D isotope dependence of the $\mathrm{N}-\mathrm{H}$ OPB motion would be the easiest to follow. For instance, in $\mathrm{H}_{2}$ TAP the OPB mode is 1 of only $8\left(b_{2 g}\right)$ normal modes, while the $\mathrm{N}-\mathrm{H}$ stretch should be the most difficult, being 1 of $17\left(a_{g}\right)$ modes. In $\mathrm{H}_{2}$ TBP, this stretching mode is 1 of 31 modes. However, as we have found experimentally for $\mathrm{H}_{2} \mathrm{Pc}$, identifying the OP bending in H/D substitution is far from obvious when the frequency of some modes increase in $D_{2} P c !^{6}$ The contrasting behaviour of these modes arises, as will be elaborated later, for two reasons. The first is that the $\mathrm{N}-\mathrm{H}$ stretch modes occur at high frequencies, energetically distinct from all other modes except for the $\mathrm{C}-\mathrm{H}$ stretching modes, while the IPB and OPB modes occur in congested regions where multiple mode crossings occur. The second reason is that the internal $\mathrm{N}-\mathrm{H}$ stretching modes are very well localized on the $\mathrm{N}-\mathrm{H}$ bonds. In contrast, avoided crossings occur in the IP and OP bending motions, rendering mode attributions in the deuterium isotopologue difficult.

\section{$\mathrm{N}-\mathrm{H}$ stretching $\left(a_{g}\right.$ and $\left.b_{1 u}\right)$ modes}

The frequencies of the $\mathrm{N}-\mathrm{H}$ stretching modes are shown in Figs. 2 and 3 for the 4 free-base tetrapyrrole molecules studied, as a function of incrementally increasing the $\mathrm{H}$-atom mass from 1 to $2 \mathrm{amu}$. Taking porphine $\left(\mathrm{H}_{2} \mathrm{P}\right)$ as an example, shown on the upper left in Fig. 2, the Raman-active (but weak) $a_{g}$ $\mathrm{N}-\mathrm{H}$ stretching mode crosses directly over three $\mathrm{C}-\mathrm{H}$ stretching modes and continues to decrease monotonically from $3593.5 \mathrm{~cm}^{-1}$ in $\mathrm{H}_{2} \mathrm{P}$ to $2638.3 \mathrm{~cm}^{-1}$ in $\mathrm{D}_{2} \mathrm{P}$. This corresponds to a shift of $955.2 \mathrm{~cm}^{-1}$ and a $v_{\mathrm{H}} / \nu_{\mathrm{D}}$ (ISR) ratio of 1.362 . This is close to the expected value of approximately $\sqrt{ } 2$ for $H / D$ isotopic substitution of a normal mode involving nearly pure $\mathrm{N}-\mathrm{H}$ motion. ${ }^{16}$ The solid curve in Fig. 2 shows the theoretical mass dependence $\left(1 / \sqrt{ } m_{\mathrm{H}}\right)$ given by eq. [1]. It is evident that the agreement between the DFT predicted data and this theoretical dependence is good.

The mass dependence of the (strong) IR-active $b_{1 u}$ mode, shown on the upper left in Fig. 3, exhibits a similar pattern with the $\mathrm{N}-\mathrm{H}$ stretch at $3552.3 \mathrm{~cm}^{-1}$ in $\mathrm{H}_{2} \mathrm{P}$, crossing over three $\mathrm{C}-\mathrm{H}$ stretches as the masses of the central hydrogens are increased. The N-D mode has a frequency of $2611.9 \mathrm{~cm}^{-1}$, which gives a $v_{\mathrm{H}} / \nu_{\mathrm{D}}$ ratio of 1.360. As illustrated in Fig. 3, this pattern is observed for the 3 other molecules studied. $\mathrm{H}_{2}$ TAP is the simplest system having the least amount of $\mathrm{C}-\mathrm{H}$ modes, just 2 in number. In contrast, the tetra-aryl molecules, $\mathrm{H}_{2} \mathrm{TBP}$ and $\mathrm{H}_{2} \mathrm{Pc}$, have numerous $\mathrm{C}-\mathrm{H}$ modes. However in all cases,

Note: The atom labelling follows standard notation used in our previous work on $\mathrm{H}_{2} \mathrm{Pc}^{6}$ 
Fig. 2. Dependence of the vibrational frequencies of the Ramanactive N-H stretch ( $a_{g}$ symmetry) normal modes of the $4\left(D_{2 h}\right)$ free-base tetrapyrrole molecules with H/D isotope substitution of the two inner hydrogens. The values shown are harmonic results calculated by increasing the $\mathrm{H}$ mass from 1 to 2 in increments of $0.05 \mathrm{amu}$. The solid trace provides the predicted inverse dependence of the frequency on the square root of the mass, indicating close agreement with the calculated values. The frequencies of the $\mathrm{C}-\mathrm{H}$ stretching modes are completely unaffected by the H/D isotope substitution of the two inner hydrogens.
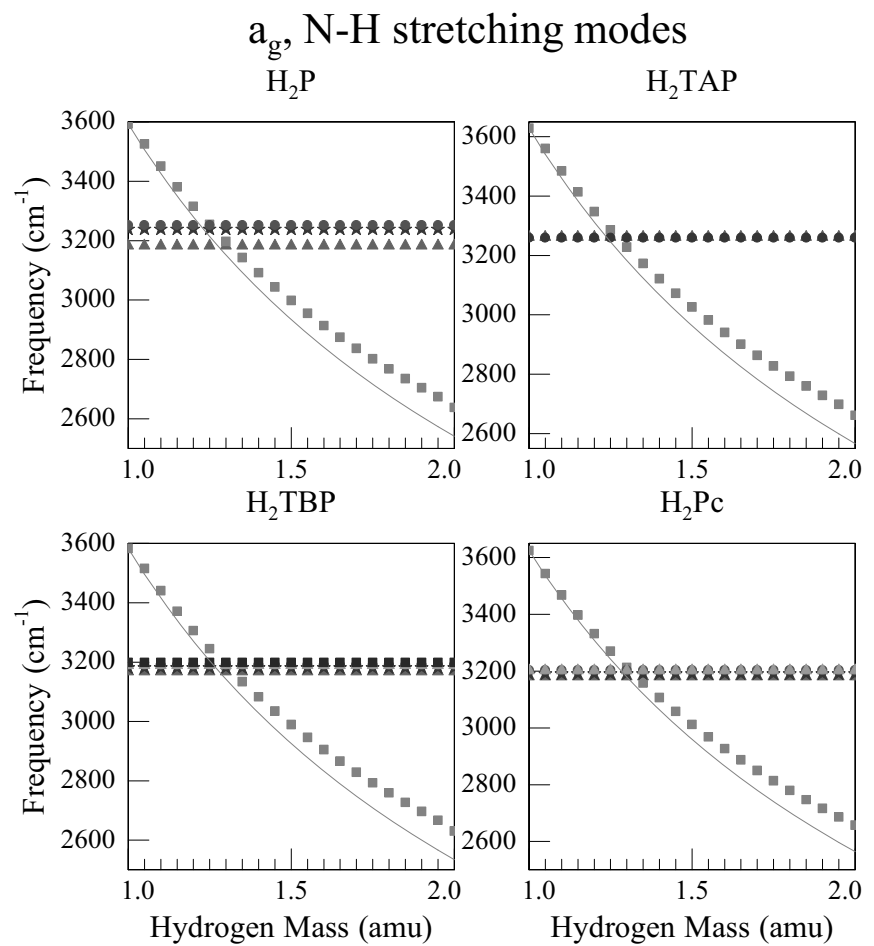

direct crossings of the normal modes occur indicating the absence of coupling between $\mathrm{N}-\mathrm{H}(\mathrm{D})$ stretching modes and $\mathrm{C}-\mathrm{H}$ stretching modes.

The frequencies of the $\mathrm{N}-\mathrm{H}$ stretching modes of $\mathrm{H}_{2} \mathrm{P}$, $\mathrm{H}_{2}$ TAP, $\mathrm{H}_{2}$ TBP, and $\mathrm{H}_{2} \mathrm{Pc}$ are collected in the upper section of Table 3 for the light and heavy isotopologues. The ISR $\left(\nu_{\mathrm{H}} / \nu_{\mathrm{D}}\right)$ values calculated from these frequencies are listed for the two $\left(a_{g}\right.$ and $\left.b_{1 u}\right)$ symmetries involved. From the values provided in Table 3 , it is clear that the ISR values span a small range, from 1.364 for the $a_{g}$ mode of phthalocyanine (Pc) to 1.360 for the $b_{1 u}$ mode of porphine $(\mathrm{P})$. It is evident that for both symmetries, presented in Figs. 2 and 3, respectively, the N-H stretching mode passes directly through the $\mathrm{C}-\mathrm{H}$ stretching modes in all four molecules without any interaction amongst these highfrequency modes. An examination of the $\mathrm{C}-\mathrm{H}$ stretching modes reveals that the changes in their frequencies, after being crossed by the $\mathrm{N}-\mathrm{H}$ modes, are extremely small. In all cases, except TBP where it is $0.04 \mathrm{~cm}^{-1}$, these changes are in the third decimal place. With this small magnitude, these shifts are less than the uncertainty of the method and are not considered significant.

An analysis of the internal modes reveals the small deviation of the calculated ISR values (1.36) from $\sqrt{ } 2$ arises from the involvement of the pyrrole ring deformation that accom-
Fig. 3. Similar to Fig. 2 except for the IR-active $b_{1 u}$ symmetry normal modes.
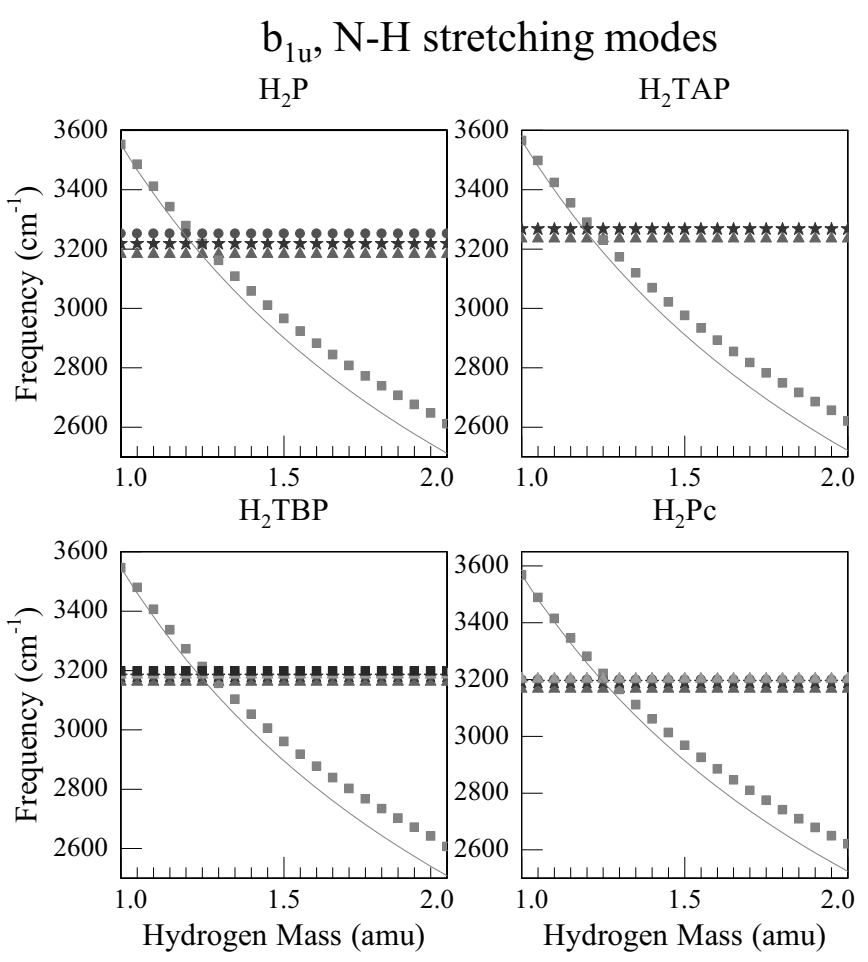

panies the $\mathrm{N}-\mathrm{H}$ stretching motion for kinematic reasons. No other internal motions are involved in these nearly pure $\mathrm{NH}(\mathrm{D})$ stretching modes. See the upper panels of Tables 4 and 5 for details of the $\%$ internal $\mathrm{N}-\mathrm{H}$ motions of these modes in the smaller tetrapyrroles, TAP and porphine, respectively.

OPB $\left(b_{3 u}\right.$ and $\left.b_{2 g}\right)$ modes

\section{$b_{3 u} N-H$ bending modes}

The mass dependences of the $b_{3 u}$ OPB modes of P, TAP, TBP, and Pc are shown in the 4 panels of Fig. 4. In the frequency range $800-550 \mathrm{~cm}^{-1}$ presented in these plots, all 4 molecules show the same number of normal modes, and the mass dependence is clearly not simple in any of them. ${ }^{17}$ Most conspicuous is the pronounced avoided crossing that occurs between two modes in the central section of the P and TAP plots. In both cases a normal mode that starts out strongly mass dependent, and is an $\mathrm{N}-\mathrm{H}$ OPB motion, becomes mass independent and evolves into a mode that involves large amplitude C-H OPBs. This is clearly not a correct mode attribution of the light to the heavy isotopologues. To help analyse the complex behaviour exhibited, the theoretical mass dependence given by eq. [1] is overlaid as a solid trace in Fig. 4. This curve, in contrast with the previous ones generated for the $a_{g}$ and $b_{1 u}$ modes, was calculated from the lowest frequency $D_{2}$ mode, because the N-H OPB motion is manifested more strongly in the heavier isotopologues of these molecules than in the lighter ones (corresponding to a less congested spectral region for $b_{3 u}$ modes). The internal mode analysis provided in Table 4 for TAP shows the contribution in $\mathrm{D}_{2} \mathrm{TAP}$ as $72 \%$, while it is only $53 \%$ in $\mathrm{H}_{2}$ TAP. Table 5 reveals a similar pattern for the $b_{3 u}$ mode of porphine. 
Table 3. H/D isotope shifts for the 6 internal N-H modes of the 4 tetrapyrrole molecules studied.

\begin{tabular}{|c|c|c|c|c|c|c|c|c|c|}
\hline Motion & Molecule & $v_{\mathrm{H}_{2}}$ & $v_{\mathrm{D}_{2}}$ & Shift & $\nu_{\mathrm{H}} / \nu_{\mathrm{D}}$ & $v_{\mathrm{H}_{2}}$ & $v_{\mathrm{D}_{2}}$ & Shift & $\nu_{\mathrm{H}} / \nu_{\mathrm{D}}$ \\
\hline \multirow[t]{5}{*}{$\mathrm{N}-\mathrm{H}$ stretch } & & $b_{1 u}$ & & & & $a_{g}$ & & & \\
\hline & $\mathrm{P}$ & 3552.34 & 2611.88 & 940.46 & 1.3601 & 3593.47 & 2638.31 & 955.16 & 1.3620 \\
\hline & TAP & 3565.39 & 2621.13 & 944.25 & 1.3602 & 3629.13 & 2661.83 & 967.30 & 1.3634 \\
\hline & ТВP & 3546.71 & 2606.78 & 939.93 & 1.3606 & 3583.25 & 2630.36 & 952.89 & 1.3623 \\
\hline & $\mathrm{Pc}$ & 3569.08 & 2621.36 & 947.73 & 1.3615 & 3625.17 & 2657.21 & 967.96 & 1.3643 \\
\hline \multirow[t]{11}{*}{ N-H OP Bend } & & $b_{3 u}$ & & & & $b_{2 g}$ & & & \\
\hline & $\mathrm{P}$ & 739.89 & 541.8 & 198.09 & 1.3656 & 631.22 & 473.78 & 157.44 & 1.3323 \\
\hline & & 651.38 & 657.91 & -6.53 & 0.9901 & $N C$ & $N C$ & & \\
\hline & TAP & 760.83 & 547.66 & 213.17 & 1.3892 & 641.4 & 479.74 & 161.66 & 1.3370 \\
\hline & & 656.65 & 664.47 & -7.82 & 0.9882 & $N C$ & $N C$ & & \\
\hline & TBP & 766.76 & 560.41 & 206.35 & 1.3682 & 711.65 & 520.08 & 191.57 & 1.3683 \\
\hline & & 713.22 & 720.33 & -7.11 & 0.9901 & 689.24 & 695.66 & -6.42 & 0.9908 \\
\hline & & 684.58 & 684.84 & -0.26 & 0.9996 & 637.72 & 638.56 & -0.84 & 0.9987 \\
\hline & $\mathrm{Pc}$ & 778.36 & 566.31 & 212.05 & 1.3744 & 680.33 & 495.23 & 185.1 & 1.3738 \\
\hline & & 740.49 & 746.78 & -6.29 & 0.9916 & 657.47 & 659.1 & -1.63 & 0.9975 \\
\hline & & 704.03 & 704.28 & -0.25 & 0.9996 & 505.86 & 511.42 & -5.56 & 0.9891 \\
\hline \multirow[t]{9}{*}{$\mathrm{N}-\mathrm{H}$ IP Bend } & & $b_{2 u}$ & & & & $b_{3 g}$ & & & \\
\hline & $\mathrm{P}$ & 1003.52 & 882.82 & 120.7 & 1.1367 & 1264.1 & 1184.6 & 79.5 & 1.0671 \\
\hline & & 967.16 & 967.43 & -0.27 & 0.9997 & 1213.11 & 1214.33 & -1.22 & 0.9990 \\
\hline & TAP & 970.33 & 851.43 & 118.9 & 1.1396 & 1250.89 & 1240.82 & 10.07 & $1.008 *$ \\
\hline & & 957.24 & 957.49 & -0.25 & 0.9997 & 1216.82 & 1202.66 & 14.16 & $1.012 *$ \\
\hline & TBP & 1067.7 & 989.03 & 78.67 & 1.0795 & 1253.59 & 1181.6 & 71.99 & 1.0609 \\
\hline & & 1038.52 & 1038.81 & -0.29 & 0.9997 & 1217.56 & 1218.7 & -1.14 & 0.9991 \\
\hline & $\mathrm{Pc}$ & 1068.39 & 981.15 & 87.24 & 1.0889 & 1223.56 & 1191.4 & 32.16 & 1.0270 \\
\hline & & 1029.31 & 1029.37 & -0.06 & 0.9999 & 1211.42 & 1211.42 & 0 & 1.0000 \\
\hline
\end{tabular}

Note: All frequencies are unscaled DFT results given in $\mathrm{cm}^{-1}$. The isotope shift ratios (ISR) are calculated as $\nu \mathrm{H} / \nu \mathrm{D}$, i.e., the hydrogen frequency divided by the deuterium value. ISR values significantly less than one are highlighted as they are indicative of strongly avoided crossings.

*No curve crossings occur between these two modes in TAP. The values chosen for inclusion were selected on the basis of the similarities of their motion with the three other tetrapyrrole molecules.

From the match shown for $\mathrm{P}$ in the upper left panel of Fig. 4, between the calculated data and the simple $1 / \sqrt{ } / \mathrm{m}_{\mathrm{H}}$ massdependence, it is clear that the frequency of the "pure" $\mathrm{N}-\mathrm{H}$ OP mode decreases from $739.9 \mathrm{~cm}^{-1}$ in $\mathrm{H}_{2} \mathrm{P}$ to $541.8 \mathrm{~cm}^{-1}$ in $\mathrm{D}_{2} \mathrm{P}$. The resulting $v_{\mathrm{H}} / \nu_{\mathrm{D}}$ ratio is 1.366 , quite close to the expected value of $\sqrt{ } 2$. This mode crosses a pure $\mathrm{C}-\mathrm{H}$ OPB with a frequency of $709.5 \mathrm{~cm}^{-1}$, which is $\mathrm{H}$-atom massindependent and is thereby not affected by the $\mathrm{N}-\mathrm{H}$ isotopic substitution. In contrast, it produces an avoided crossing with another $\mathrm{C}-\mathrm{H}$ OPB mode, which has an initial value of $651.4 \mathrm{~cm}^{-1}$ in $\mathrm{H}_{2} \mathrm{P}$ but increases to $657.9 \mathrm{~cm}^{-1}$ in $\mathrm{D}_{2} \mathrm{P}$. A clear consequence of the avoided crossing is that this mode shifts up in frequency by $6.53 \mathrm{~cm}^{-1}$ and produces an ISR value $\left(\nu_{\mathrm{H}} / \nu_{\mathrm{D}}\right.$ ratio) considerably less than unity - the value is 0.9901 . As indicted in Table 3, similar behaviour is exhibited by this mode in all 4 molecules. The most extreme situation is found for TAP, which has an ISR value of 0.9882 .

Figure 5 shows a vector diagram for the atomic motions involved in the modes of TAP that exhibits the most pronounced reversed ISR effect. From the motions presented, the association of the $760.8 \mathrm{~cm}^{-1}$ mode with the $547.7 \mathrm{~cm}^{-1}$ mode is unquestionable. Thus as illustrated, the vector diagrams for the N-H OPB motions of $\mathrm{H}_{2}$ TAP and $\mathrm{D}_{2}$ TAP are indistinguishable for these two frequencies. However, a consequence of these mode assignments is that the mode at $656.7 \mathrm{~cm}^{-1}$ must be correlated with that at $664.5 \mathrm{~cm}^{-1}$, an upward shift of $7.82 \mathrm{~cm}^{-1}$ in $\mathrm{D}_{2}$ TAP. This correlation is supported by the very similar C-H OPB motions illustrated for both isotopologues on the bottom of Fig. 5. However, on closer scrutiny of these two diagrams it can be seen that the direction of the $\mathrm{N}-\mathrm{H}$ bending motion with respect to the molecule is reversed in the N-D mode. This change in the motion of the light and heavy isotopologues is found to be a characteristic of all the modes exhibiting the large reverse ISR, which involve strongly avoided mode crossings.

Reverse ISRs are observed to be larger in cases with more pronounced avoided crossings, i.e., with stronger coupling, $W$, between the modes. The reversal of the directions of the $\mathrm{H}$-atom motions in the light and heavy species can be seen as a direct consequence of perturbation theory in first order. In the simplified case of two coupled modes, one mode, $v_{\mathrm{H}}$, involving large $\mathrm{H}$ motion and the other, $v_{\mathrm{N}}$, involving little $\mathrm{H}$ motion as is the case for when the $\mathrm{H} \rightarrow \mathrm{D}$ progression is very flat except in the region of the crossing, the result of perturbation theory will give new modes $\nu^{\prime}{ }_{\mathrm{N}}$ with $\left|v^{\prime}{ }_{\mathrm{N}}\right\rangle=\left|v_{\mathrm{N}}\right\rangle+$ $W /\left(E_{\mathrm{nN}}-E_{\mathrm{nH}}\right)\left|v_{\mathrm{H}}\right\rangle$. The reason for the reversed directions can be understood as follows. Since the sign of the matrix element $W\left(=\left\langle v_{\mathrm{H}}|W| v_{\mathrm{N}}\right\rangle\right)$ does not change from $\mathrm{H}$ to $\mathrm{D}$, but it does change for the energy term, i.e., $\left(E_{\mathrm{nN}}-E_{\mathrm{nH}}\right)<0$ for $H$, whereas $\left(E_{\mathrm{nN}}-E_{\mathrm{nH}}\right)>0$ for $\mathrm{D}$, this means that the motion of $H\left(\left|m_{\mathrm{H}}\right\rangle\right)$ appears with opposite signs in the description of $\left|v_{\mathrm{N}}\right\rangle$ in the hydrogenated and the deuterated species, i.e., reversal of directions. This "reversal" is larger and more obvious when the coupling $W$ strength is greater. 
Table 4. Contributions of the $\mathrm{N}-\mathrm{H}$ internal modes to the normal modes involving crossings, or avoided crossings of TAP.

\begin{tabular}{|c|c|c|c|c|c|c|c|}
\hline \multirow[b]{2}{*}{ Sym. } & \multicolumn{3}{|l|}{$\mathrm{H}_{2}$ TAP } & \multicolumn{3}{|l|}{$\underline{\mathrm{D}_{2} \mathrm{TAP}}$} & \multirow{2}{*}{$\begin{array}{l}\mathrm{ISR} \\
\nu \mathrm{H} / \nu \mathrm{D}\end{array}$} \\
\hline & Mode\# & Frequency & $\%$ Int. Mode & Mode\# & Frequency & $\%$ Int. Mode & \\
\hline$a_{g}$ & 96 & 3629.13 & $68 \% \mathrm{~N}-\mathrm{H}$ stretch & 88 & 2661.83 & $61.6 \%$ N-D stretch & 1.3634 \\
\hline$b_{1 u}$ & 95 & 3565.38 & $68 \% \mathrm{~N}-\mathrm{H}$ stretch & 87 & 2621.13 & $62.4 \%$ N-D stretch & 1.3602 \\
\hline$b_{2 g}$ & 23 & 641.4 & $54.8 \%$ N-H OPB & 22 & 479.73 & $68.4 \%$ N-D OPB & 1.3370 \\
\hline$b_{3 u}$ & $\begin{array}{l}36 \\
24\end{array}$ & $\begin{array}{l}760.82 \\
656.65\end{array}$ & $\begin{array}{l}52.8 \% \text { N-H OPB } \\
22.4 \% \text { N-H OPB }\end{array}$ & $\begin{array}{l}24 \\
25\end{array}$ & $\begin{array}{l}547.66 \\
664.46\end{array}$ & $\begin{array}{l}72 \% \text { N-D OPB } \\
7.6 \% \text { N-D OPB }\end{array}$ & $\begin{array}{l}1.3892 \\
\mathbf{0 . 9 8 8 2}\end{array}$ \\
\hline$b_{2 u}$ & $\begin{array}{l}67 \\
63 \\
52 \\
51 \\
38 \\
33\end{array}$ & $\begin{array}{r}1266.18 \\
1198.73 \\
970.32 \\
957.23 \\
776.51 \\
748.85\end{array}$ & $\begin{array}{l}21.2 \% \text { N-H IPB } \\
18.8 \% \text { N-H IPB } \\
19.2 \% \text { N-H IPB } \\
4 \% \text { N-H IPB } \\
10.8 \% \text { N-H IPB } \\
2 \% \text { N-H IPB }\end{array}$ & $\begin{array}{l}66 \\
62 \\
46 \\
52 \\
33 \\
36\end{array}$ & $\begin{array}{r}1242.04 \\
1116.18 \\
851.42 \\
957.49 \\
726.39 \\
754.00\end{array}$ & $\begin{array}{l}7.6 \% \text { N-D IPB } \\
18 \% \text { N-D IPB } \\
24 \% \text { N-D IPB } \\
0 \% \text { N-D IPB } \\
23.2 \% \text { N-D IPB } \\
9.6 \% \text { N-D IPB }\end{array}$ & $\begin{array}{l}1.0194 \\
1.0740 \\
1.1396 \\
0.9997 \\
1.0690 \\
\mathbf{0 . 9 9 3 2}\end{array}$ \\
\hline$b_{3 g}$ & $\begin{array}{l}62 \\
65 \\
64 \\
49 \\
39\end{array}$ & $\begin{array}{r}1164.35 \\
1250.89 \\
1216.82 \\
950.62 \\
778.95\end{array}$ & $\begin{array}{l}20.4 \% \text { N-H IPB } \\
15.6 \% \text { N-H IPB } \\
11.2 \% \text { N-H IPB } \\
26.4 \% \text { N-H IPB } \\
14 \% \text { N-H IPB }\end{array}$ & $\begin{array}{l}61 \\
65 \\
65 \\
45 \\
29\end{array}$ & $\begin{array}{r}1108.93 \\
1240.82 \\
1202.66 \\
849.92 \\
711.09\end{array}$ & $\begin{array}{l}17.2 \% \text { N-D IPB } \\
6 \% \text { N-D IPB } \\
4.8 \% \text { N-D IPB } \\
16.8 \% \text { N-D IPB } \\
30 \% \text { N-D IPB }\end{array}$ & $\begin{array}{l}1.0500 \\
1.0081 \\
1.0118 \\
1.1185 \\
1.0954\end{array}$ \\
\hline
\end{tabular}

Note: Avoided crossings are easily identified when the ISR values are less than 1. Instances with particularly strong coupling, producing large avoided crossings, are highlighted in boldface.

Table 5. Contributions of the $\mathrm{N}-\mathrm{H}$ internal modes to the normal modes involving crossings, or avoided crossings of porphine.

\begin{tabular}{|c|c|c|c|c|c|c|c|}
\hline \multirow[b]{2}{*}{ Sym } & \multicolumn{3}{|l|}{$\mathrm{H}_{2} \mathrm{P}$} & \multicolumn{3}{|l|}{$\underline{\mathrm{D}_{2} \mathrm{P}}$} & \multirow{2}{*}{$\begin{array}{l}\text { ISR } \\
\nu \mathrm{H} / \nu \mathrm{D}\end{array}$} \\
\hline & Mode & Frequency & $\%$ Int. Mode & Mode & Frequency & $\%$ Int. Mode & \\
\hline$a_{g}$ & 108 & 3593.47 & $77.8 \% \mathrm{~N}-\mathrm{H}$ stretch & 96 & 2638.31 & $61.2 \%$ N-D stretch & 1.3620 \\
\hline$b_{1 u}$ & 107 & 3552.34 & $77.8 \% \mathrm{~N}-\mathrm{H}$ stretch & 95 & 2611.88 & $61.4 \%$ N-D stretch & 1.3601 \\
\hline$b_{2 g}$ & 23 & 631.22 & $50.8 \% \mathrm{~N}-\mathrm{H}$ OPB & 22 & 473.78 & $65.2 \% \mathrm{~N}-\mathrm{D}$ OPB & 1.3323 \\
\hline$b_{3 u}$ & $\begin{array}{l}35 \\
24\end{array}$ & $\begin{array}{l}739.89 \\
651.38\end{array}$ & $\begin{array}{l}32 \% \text { N-H OPB } \\
21.2 \% \text { N-H OPB }\end{array}$ & $\begin{array}{l}24 \\
25\end{array}$ & $\begin{array}{l}541.81 \\
657.91\end{array}$ & $\begin{array}{l}70.4 \% \text { N-D OPB } \\
8.4 \% \text { N-D OPB }\end{array}$ & $\begin{array}{l}1.3656 \\
\mathbf{0 . 9 9 0 1}\end{array}$ \\
\hline$b_{2 u}$ & $\begin{array}{l}71 \\
67 \\
57 \\
53 \\
41\end{array}$ & $\begin{array}{r}1260.59 \\
1179.31 \\
1003.52 \\
967.16 \\
796.36\end{array}$ & $\begin{array}{l}26 \% \text { N-H IPB } \\
7.6 \% \text { N-H IPB } \\
14.8 \% \text { N-H IPB } \\
1.6 \% \text { N-H IPB } \\
8 \% \text { N-H IPB }\end{array}$ & $\begin{array}{l}65 \\
69 \\
50 \\
55 \\
38\end{array}$ & $\begin{array}{r}1120.28 \\
1195.31 \\
882.81 \\
967.44 \\
759.71\end{array}$ & $\begin{array}{l}16.4 \% \text { N-D IPB } \\
8 \% \text { N-D IPB } \\
27.2 \% \text { N-D IPB } \\
0 \% \text { N-D IPB } \\
18 \% \text { N-D IPB }\end{array}$ & $\begin{array}{l}1.1252 \\
\mathbf{0 . 9 8 6 6} \\
1.1367 \\
0.9997 \\
1.0482\end{array}$ \\
\hline$b_{3 g}$ & $\begin{array}{l}72 \\
69 \\
56 \\
43\end{array}$ & $\begin{array}{r}1264.10 \\
1213.11 \\
992.92 \\
800.34\end{array}$ & $\begin{array}{l}26.4 \% \text { N-H IPB } \\
4 \% \text { N-H IPB } \\
16.8 \% \text { N-H IPB } \\
8.8 \% \text { N-H IPB }\end{array}$ & $\begin{array}{l}68 \\
72 \\
49 \\
36\end{array}$ & $\begin{array}{r}1184.59 \\
1214.33 \\
881.53 \\
752.31\end{array}$ & $\begin{array}{l}10.8 \% \text { N-D IPB } \\
0 \% \text { N-D IPB } \\
20.0 \% \text { N-D IPB } \\
24.4 \% \text { N-D IPB }\end{array}$ & $\begin{array}{l}1.0671 \\
0.9990 \\
1.1264 \\
1.0638\end{array}$ \\
\hline
\end{tabular}

Note: Avoided crossings are identified by ISR $<1$.

\section{$b_{2 g} \mathrm{~N}-\mathrm{H}$ bending modes}

The H/D isotope dependences of the Raman-active $b_{2 g}$ $\mathrm{N}-\mathrm{H}$ OPB modes of porphine and TAP are, as shown in the upper panels of Fig. 6, relatively straightforward, exhibiting a continuous mode evolution from the light to the heavy isotopologue. As indicated in Table 3, they exhibit an ISR of 1.33 and follow the simple mass dependence shown by the smooth curve in Fig. 6. In contrast, TBP and Pc are both complicated by the existence of an additional mode that is crossed by the $\mathrm{N}-\mathrm{H} b_{2 g}$ OPB mode at different locations. 
Fig. 4. Mass dependence of the IR-active $b_{3 u}$ symmetry normal modes for the OPB vibrations. In contrast to the high frequency modes, strong coupling occurs between the N-H OPB modes and especially the C-H OPB modes. This is indicated by the large avoided crossing that is clearly evident in the top two panels where $\mathrm{P}$ and TAP results are shown. A strong correlation exists between the N-H OPB modes of the light and heavy isotopologues, as indicated by the theoretical mass dependence of the frequency. However, the frequency of the C-H OPB mode "crossed" by the $\mathrm{N}-\mathrm{H}$ mode increases in the deuterated molecule, leading to reversed isotope shift ratios (ISR $<1$ ).

\section{$\mathrm{b}_{3 \mathrm{u}}$, OP bending modes}
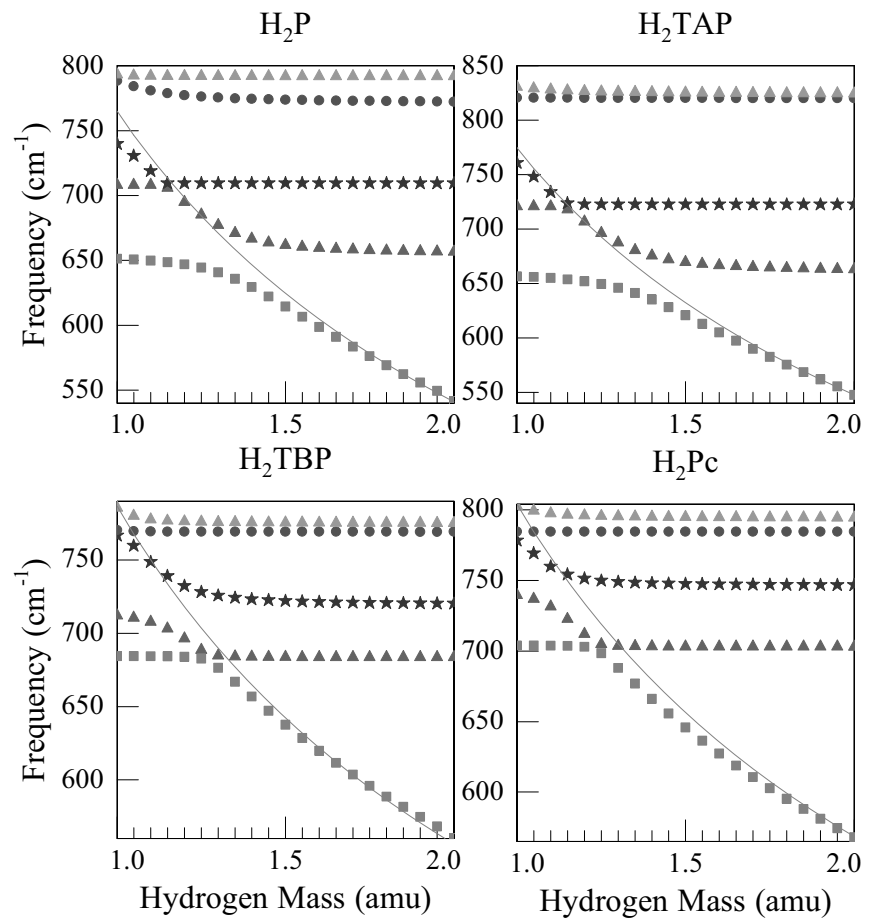

Again, the mass dependence curve is very instructive in identifying the correct mode evolution. As listed in Table 3, the $711.7 \mathrm{~cm}^{-1}$ mode of $\mathrm{H}_{2}$ TBP correlates with the $520.1 \mathrm{~cm}^{-1}$ mode of $\mathrm{D}_{2}$ TBP, giving an ISR value of 1.368; a similar value is present for phthalocyanine. However, the curve avoidance that is now present produces ISR values significantly less than 1 in both cases for the modes crossed. Table 3 lists these as 0.991 and 0.989 for TBP and Pc, respectively.

\section{IPB $\left(b_{2 u}\right.$ and $\left.b_{3 g}\right)$ modes}

Summaries of the isotope dependences of the $b_{2 u}$ and $b_{3 g}$ $\mathrm{N}-\mathrm{H}$ IPB modes are provided in Figs. 7 and 8, respectively. The mass dependences of these modes are evidently not simple but are quite similar for all 4 molecules. It is clear that these IPB modes do not show a mass dependence that is as strong as $\left(m_{\mathrm{H}}{ }^{-1 / 2}\right)$, shown by the smooth line. Instead, several modes appear to have a weak, near-linear dependence on mass. The slope of the $\left(m_{\mathrm{H}}{ }^{-1 / 2}\right)$ law is never approached, whatever the isotopologue. This effect is due to an extreme dilution of NH IP motions in many modes of the same symmetry. Modes exhibiting the highest absolute slope at $m_{\mathrm{H}}=1$ or 2 correspond in fact to the modes involving the highest \% of NH or ND IP motion, respectively. This is verified in Tables 4 and 5, where the $b_{2 u}$ and $b_{3 g}$ modes exhibiting the highest $\%$ are reported for TAP and P, respectively.

\section{$b_{2 u} N-H$ bending modes}

Some mode crossings do occur for the $b_{2 u} \mathrm{~N}-\mathrm{H}$ IPB motion, and because of the similarity of the behaviour in the midfrequency region for all 4 molecules, the modes in the 850$1070 \mathrm{~cm}^{-1}$ range have been chosen for inclusion in Table 3 .

The IR-active $b_{2 u}$ modes of porphine and TAP are quite similar, showing a diluted effect upon isotopic substitution of the inner hydrogens. As listed in Table 3, the mode at $1003.5 \mathrm{~cm}^{-1}$ in $\mathrm{H}_{2} \mathrm{P}$, involving an $\mathrm{N}-\mathrm{H}$ IPB, drops down to $882.8 \mathrm{~cm}^{-1}$ in $\mathrm{D}_{2} \mathrm{P}$. This shift corresponds to a $\nu_{\mathrm{H}} / \nu_{\mathrm{D}}$ ratio of only 1.137 , a value much less than $\sqrt{ } 2$. This mode shows a weak avoided crossing with the one at $967.2 \mathrm{~cm}^{-1}$, a pyrrole ring stretching mode. This avoided crossing has the effect of increasing the frequency of the pyrrole ring stretching mode in $\mathrm{D}_{2} \mathrm{P}$ by a small amount to $967.4 \mathrm{~cm}^{-1}$ and generating a $\nu_{\mathrm{H}} / \nu_{\mathrm{D}}$ ratio of 0.9997 . While the $0.27 \mathrm{~cm}^{-1}$ shift in frequency for the pyrrole mode is small, similar values are exhibited by all the tetrapyrroles, except Pc where it is yet smaller, $0.06 \mathrm{~cm}^{-1}$. The significance of these ISR values is hard to ascertain because while they are consistently less than 1, they are very close to it. It is worth noting however that for the pure $\mathrm{C}-\mathrm{H}$ stretching $a_{g}$ and $b_{1 u}$ modes crossed over by the N-H(D) mode (see Figs. 2 and 3), the ISR values are much closer to 1 . In the present IPB $b_{2 u}$ mode, vector diagrams indicate that there is some $\mathrm{N}-\mathrm{H}$ character in the pyrrole ring stretch, so the small ISR values are deemed significant.

While not included in the global ISR summary provided in Table 3, it is evident in Fig. 7 that mode crossings do occur in the lower frequency range, but the crossing regions vary from molecule to molecule. Thus direct crossings are exhibited by $\mathrm{P}$ and Pc, while avoided crossings are present in TAP and TBP. Information on the avoided crossing in the former is provided in Table 4, where the $776.5 \mathrm{~cm}^{-1}$ mode of $\mathrm{H}_{2}$ TAP decreases to $726.4 \mathrm{~cm}^{-1}$ for $\mathrm{D}_{2}$ TAP with a small ISR value of 1.069 . However, this then produces a frequency increase in the interacting mode at $748.9 \mathrm{~cm}^{-1}$ that moves up to $754.0 \mathrm{~cm}^{-1}$ in $\mathrm{D}_{2}$ TAP and has an ISR significantly less than 1 , with a value of 0.9932. Porphine does not exhibit this behaviour, so a corresponding value is not given in Table 5 .

In the higher frequency region, only $\mathrm{P}$ and TBP exhibit avoided crossings and detailed information on the behaviour of porphine is presented in Table 5. It is evident there that a reverse ISR is present with an upward frequency shift of $16 \mathrm{~cm}^{-1}$, producing an ISR value of 0.9866 . Thus the highest frequency $\mathrm{N}-\mathrm{H}$ IPB mode at $1260.6 \mathrm{~cm}^{-1}$ correlates with the $1120.3 \mathrm{~cm}^{-1}$ mode of $\mathrm{D}_{2} \mathrm{P}$, yielding a diminished ISR of 1.125 . A consequence of this attribution is that the $\mathrm{H}_{2} \mathrm{P}$ mode at $1179.3 \mathrm{~cm}^{-1}$ must be associated with the $1195.3 \mathrm{~cm}^{-1}$ mode of $\mathrm{D}_{2} \mathrm{P}$. An upward shift of $108 \mathrm{~cm}^{-1}$ was previously highlighted by $\mathrm{Li}$ et al. for a $b_{2 u}$ symmetry asymmetric deformation, $\delta_{\text {as }}(\mathrm{NH})$, mode. ${ }^{8}$ However, this earlier correlation involved modes at 986 and $1094 \mathrm{~cm}^{-1}$, which do not correspond to the present ones at 1179 and $1195 \mathrm{~cm}^{-1}$. 
Fig. 5. Vector diagrams showing the very similar atomic motions involved in the pure N-H OPB motion of TAP for the hydrogenated and deuterated molecules, top left and right, respectively. In the bottom, the motions in the $\mathrm{C}-\mathrm{H}$ mode involved in the avoided crossing with the N-H OPB are shown. The $656 / 664 \mathrm{~cm}^{-1}$ mode correlations of the two istopomers are clearly correct. However, on closer scrutiny it is evident that the direction of the small $\mathrm{N}-\mathrm{H}$ motion, which this mode possesses, is reversed in the $\mathrm{H}$ and $\mathrm{D}$ molecules. This behavior is exhibited in all the modes involved in the avoided crossings.
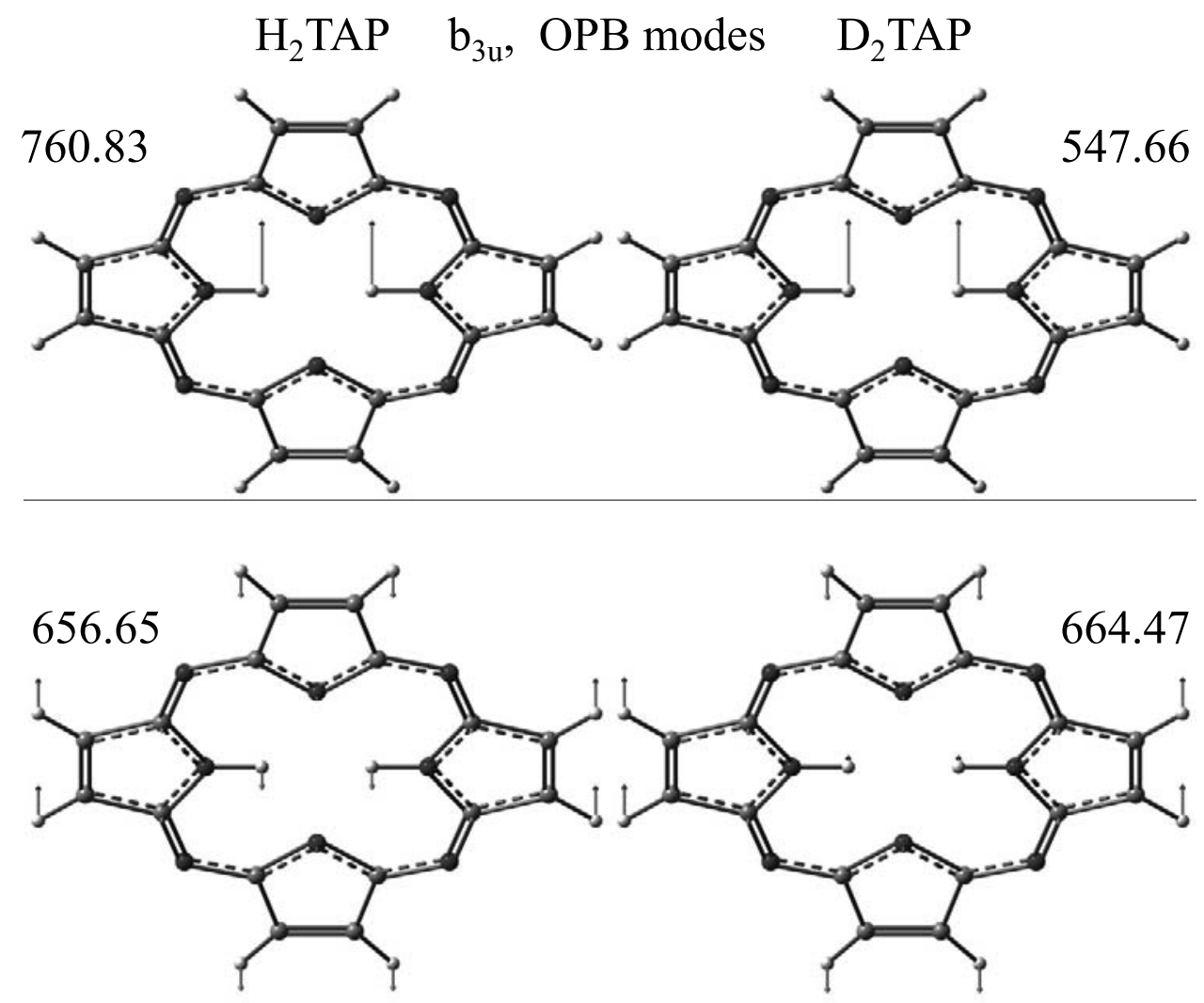

\section{$b_{3 g} I P B N-H$ modes}

The Raman-active $b_{3 g}$ modes presented in Fig. 8 exhibit similar behaviour to the IR-active $b_{2 u}$ modes, but the mass dependence is even more diluted. This dilution effect is extreme in the case of the larger molecules TBP and Pc, where every mode, except one at $1140 \mathrm{~cm}^{-1}$, shows a slight mass dependence. As a result, most of the modes are parallel, which mitigates against curve crossings. In contrast, the behaviour in $\mathrm{P}$ and TAP is more well-defined with two modes at around 810 and $1020 \mathrm{~cm}^{-1}$, clearly mass independent, while the remainder all show some mass dependence.

Taking porphine as an example, the most "pure" N-H IPB mode (listed in Table 5 as 26.4\%) has a frequency of $1264.1 \mathrm{~cm}^{-1}$, a value that decreases to $1184.6 \mathrm{~cm}^{-1}$ as the mass is increased from 1 to $2 \mathrm{amu}$. As quoted in Table 3, this correlation produces a $\nu_{\mathrm{H}} / \nu_{\mathrm{D}}$ ratio of 1.067 , and the aforementioned mode exhibits an avoided crossing with the one at $1213.1 \mathrm{~cm}^{-1}$ involving C-H IPBs. It thereby generates a small increase in the frequency in the heavy isotopologue. This increase is listed in Table 3 as $1.22 \mathrm{~cm}^{-1}$, and when compared with TBP, consistent ISR values of 0.999 are obtained. No curve crossings occur between these two modes in TAP. The TAP values chosen for inclusion in Table 3 were selected on the basis of the similarities of their motion with the 3 other tetrapyrrole molecules.

\section{Discussion}

To examine the occurrence of the reversed ISRs, the socalled product rule presented by Wilson et al. on isotope shifts in high-symmetry molecules will now be considered. ${ }^{9}$ The general form of the product rule for isotopic substitution is given (Ref. 9, p. 248) as:

$$
\frac{\omega_{1}^{\prime} \omega_{2}^{\prime} \ldots \omega_{\mathrm{n}}^{\prime}}{\omega_{1} \omega_{2} \ldots \omega_{\mathrm{n}}}=\left[\left(\frac{\mu_{\alpha}^{\prime}}{\mu_{\alpha}}\right)^{a}\left(\frac{\mu_{\beta}^{\prime}}{\mu_{\beta}}\right)^{b} \ldots\left(\frac{M^{\prime}}{M}\right)^{t}\left(\frac{I_{x}^{\prime}}{I_{x}}\right)^{r_{x}}\left(\frac{I_{y}^{\prime}}{I_{y}}\right)^{r_{y}}\left(\frac{I_{z}^{\prime}}{I_{z}}\right)^{r_{z}}\right]^{1 / 2}
$$

Equation [2] pertains to all the vibrational frequencies $\omega_{1} \omega_{2} \ldots \omega_{\mathrm{n}}$ of a single symmetry species for the light molecule, while $\omega_{1}^{\prime} \omega_{2}^{\prime} \ldots \omega_{n}^{\prime}$ are the corresponding values of the heavy isotopologue. In eq. [2] the exponents $a, b, \ldots$ relate to the atoms being substituted, while the values of $t, r_{x}, r_{y}$, and $r_{z}$ are the translation and rotation representations, respectively. $\mu, M$, and $I$ are the reduced mass, the total molecular mass, and the moments of inertia, respectively. Appendix A presents the equations specific to the 6 vibrational modes sensitive to H/D substitution of the two inner $\mathrm{H}$-atoms for $D_{2 h}$ symmetry. A comparison of the numerical values arising from the DFT calculations done on $\mathrm{H}_{2} \mathrm{TAP} / \mathrm{D}_{2} \mathrm{TAP}$ with the theoretical values predicted by the specific equations in Appendix A is provided in Table 6. 
Fig. 6. Similar to Fig. 4 except for the Raman-active $b_{2 g}$ symmetry $\mathrm{N}-\mathrm{H}$ OPB modes. Particularly simple behaviour is exhibited in the smaller molecules $\mathrm{P}$ and TAP, as indicated by the close agreement with the solid curve showing the theoretical mass dependence.
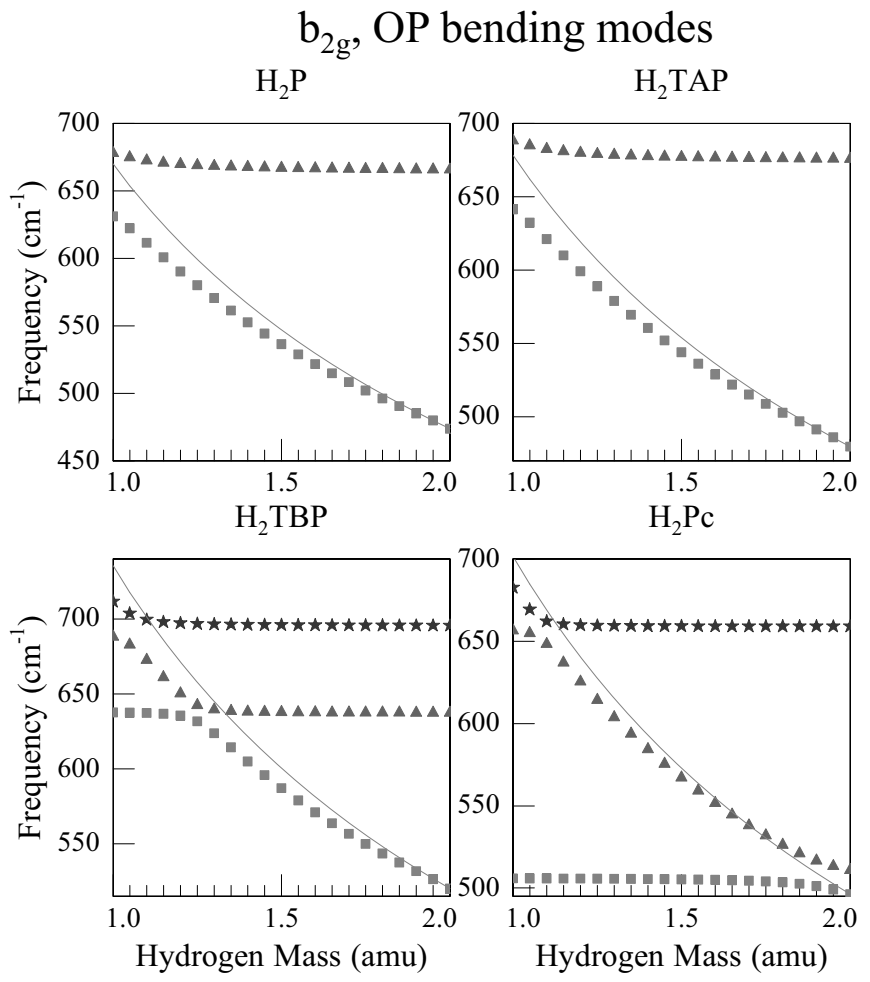

As indicated by the values given in Table 6, the product rule unfortunately does not reveal the reversed ISR effect very clearly. However, the deviations between the calculated DFT values and those predicted by eq. [2] are largest for the IPB and OPB modes. These deviations, shown on the right-hand column in Table 6, are greater than the $\mathrm{N}-\mathrm{H}$ stretch (STR) modes and the two modes where no H/D dependence is (correctly) predicted. The reason for this inability to highlight the reversed ISR is because eq. [2] involves all the modes of the same symmetry. This means that the normal modes with avoided crossings (reversed ISRs) are "compensated" by other regular modes. Despite this shortcoming, the product rule indicates the accuracy of the DFT results, as the deviations between calculation and theory are very small indeed.

\section{Comparison with other calculations}

In the detailed theoretical study carried out by $\mathrm{Li}$ and Zgierski on developing a force field for free-base porphine, upward frequency shifts were proposed for the $b_{1 g}$ and $b_{2 u}$ IPB modes upon deuteration. ${ }^{8}$ However, the previous study dealt only with the in-plane vibrations, namely the $\mathrm{N}-\mathrm{H}$ stretching and IPB modes. Because of the use of a different axis system (see Note 11) in the current and previous works, $b_{1 g}$ symmetry of Li et al. ${ }^{8}$ corresponds to our $b_{3 g}$ mode, while the $b_{2 u}$ modes are the same in both studies. In Scheme I of Ref. 8, these workers proposed a large increase in the frequency of two modes upon H/D isotopic substitution, both of which involved IPB. Specifically, they proposed that the $b_{1 g} \mathrm{~N}-\mathrm{H}$ IPB mode crosses with the a pyrrole half-ring stretch mode, which had
Fig. 7. Mass dependence of the IR-active $b_{2 u}$ symmetry for the $\mathrm{N}-\mathrm{H}$ IPB modes. Particularly evident is the large number of modes and the fact that they nearly all show a dependence on mass. This reveals immediately that the $\mathrm{N}-\mathrm{H}$ bending vibration is diluted over many modes, none of which can show the expected mass dependence of a pure mode indicated by the smooth curve.

\section{$\mathrm{b}_{2 \mathrm{u}}$, IP bending modes}

$\mathrm{H}_{2} \mathrm{P}$
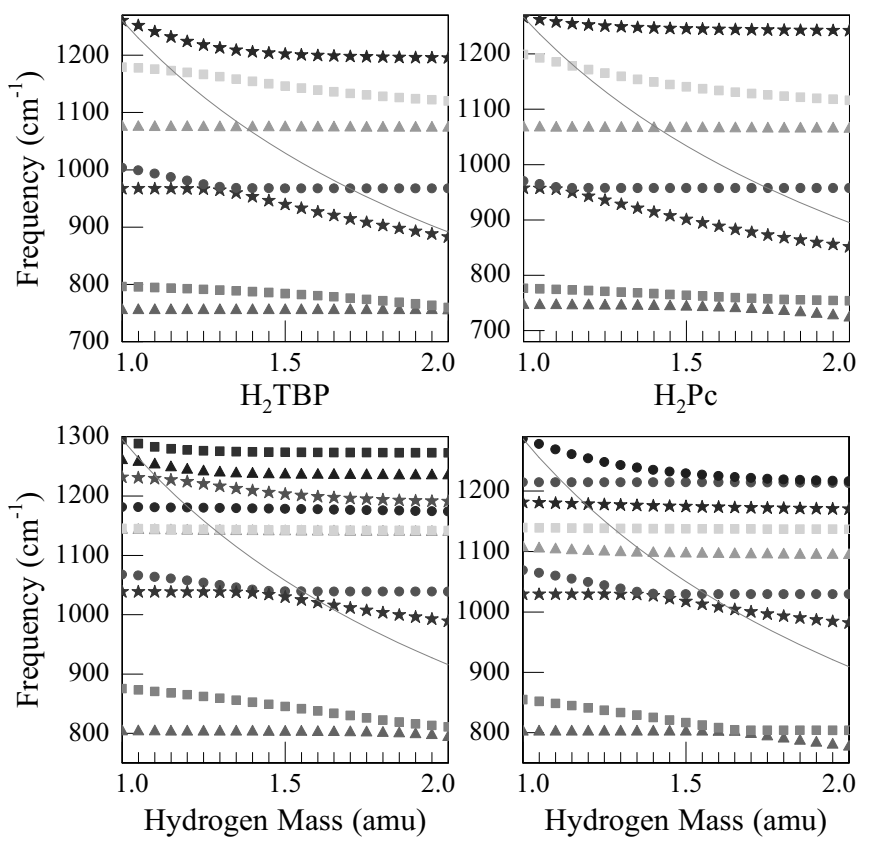

the effect of shifting the frequency of the pyrrole mode up by $56 \mathrm{~cm}^{-1}$, from $976 \mathrm{~cm}^{-1}$ in $\mathrm{H}_{2} \mathrm{P}$ to $1032 \mathrm{~cm}^{-1}$ in $\mathrm{D}_{2} \mathrm{P}$. The other mode that showed this effect was a $b_{2 u}$ mode, in which the asymmetric N-H IPB vibrations and the pyrrole ring stretch cross. This caused the pyrrole stretch to shift up in energy by $108 \mathrm{~cm}^{-1}$, from $986 \mathrm{~cm}^{-1}$ to $1094 \mathrm{~cm}^{-1}$. It is not evident why the OPB modes were not analysed for this effect in the earlier study; it may have been due to their interest in the role of the N-H stretch and IPB vibrations in the tautomerism of free-base porphine. ${ }^{8}$

As indicated in the upper left panels in Figs. 7 and 8, reverse isotope shifts of this magnitude are not exhibited by porphine in the $b_{3 g}$ and $b_{2 u}$ IPB modes, respectively. Evidently there are significant differences between Li's results ${ }^{8}$ and the findings of the present DFT method. The earlier work identified only two instances of this increased frequency, both of which are much larger than what we find. These differences may arise for a number of reasons. Their calculations were carried out with the GF matrix method and a valence force field. While their method was paramaterised to give a good match with experimental data, it is likely the valence force field is not capable of accounting for all the interactions present in molecules of this size. Complete sets of force constants are of course available from quantum chemical calculations, and the use of high level DFT calculations are currently the most powerful for predicting the ground-state vibrational frequencies of large polyatomic molecules. Based on the favourable findings of our previous DFT results on $\mathrm{ZnPc}$ and $\mathrm{H}_{2} \mathrm{Pc}$ and the matrix-IR spectra ${ }^{6}$ of these 
Fig. 8. Similar to Fig. 7 except for the Raman-active $b_{3 g}$ symmetry $\mathrm{N}-\mathrm{H}$ IPB modes.

\section{$\mathrm{b}_{3 \mathrm{~g}}$, IP bending modes}
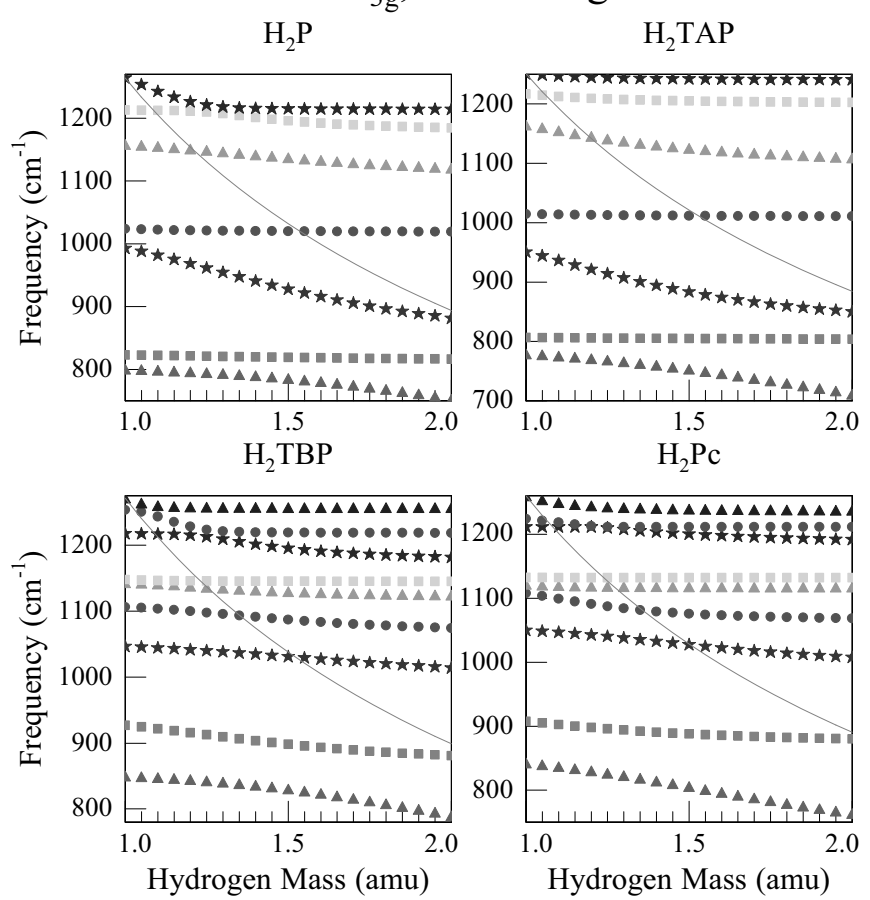

molecules, we are confident that the present results are a more accurate reflection of the extent of the up-shifted frequencies.

$\mathrm{Li}$ et al. identified the NH(D) IPB $b_{2 u}$ modes at $1223(825) \mathrm{cm}^{-1}$, corresponding to $1261(883) \mathrm{cm}^{-1}$ in our calculations. ${ }^{8}$ These modes exhibit, as listed in Table 5, the highest \% of NH(D) IPB motion. A mode which also involves non-negligible $\mathrm{NH}$ bending motions was identified at $986 \mathrm{~cm}^{-1}\left(v_{44 \mathrm{a}}\right)$ in the previous work and corresponds to the mode at $1003 \mathrm{~cm}^{-1}$ in the present work (14.8\% N-H IPB in Table 5). This mode is found to correlate with the mode at $883 \mathrm{~cm}^{-1}$ in the deuterated species, i.e., the mode involving the highest \% N-D IPB motion. In the discussed case, the entries in Table 5 show that modes at 1261 and $1003 \mathrm{~cm}^{-1}$ in the $\mathrm{H}$ species correlate with modes at 1120 and $883 \mathrm{~cm}^{-1}$, with a decrease of the $\mathrm{N}-$ " $\mathrm{H}$ " IPB $\%$ in the higher frequency mode and an increase of the N-" $\mathrm{H}$ " IPB \% in the lower frequency one, explaining the earlier result. It must be mentioned that the $b_{2 u}$ mode at $1094 \mathrm{~cm}^{-1}$ highlighted by $\mathrm{Li}$ et al. ${ }^{8}$ in the correlations for the $\mathrm{D}$ species, corresponds to a mode at $1076 \mathrm{~cm}^{-1}$ in our calculation; this mode does not involve N-D IPB motion. The discrepancies between the earlier results from $\mathrm{Li}$ et al. and the present results on $b_{3 g}$ modes of porphine are similarly explained. The curves of Fig. 7 and 8 show clearly the correlations between $\mathrm{H}$ and $\mathrm{D}$ species and are summarized in Table 5. Because of a strong mixing of various atomic motions in the $b_{3 g}$ and $b_{2 u}$ modes for the frequency range of interest, a slightly different description of normal modes can have important consequences in their assignments, as highlighted by the example in this last discussion.

\section{Comparison with experiments}

The results of the current calculations can be compared with experimental isotope substitution work, but because the mass- related shifts are quite small in the congested $1500-500 \mathrm{~cm}^{-1}$ spectral range, high-resolution methods yielding narrow line transitions are required for analysis. The matrix-isolation technique is particularly well suited for this work. Currently however, only a very limited number of tetrapyrroles have been examined in this way. One system that has been examined already is our recent work on the phthalocyanines, from which the current investigation has emerged. ${ }^{6}$ The other is the earlier study of Radziszewski et al., who used matrix-IR spectroscopy to look at deuteration effects in free-base porphine. ${ }^{18}$ To compare the present theoretical results on porphine with the experimental matrix work, ${ }^{19}$ the simulated DFT IR absorption spectra of $\mathrm{H}_{2} \mathrm{P}$ and $\mathrm{D}_{2} \mathrm{P}$ are shown scaled by a factor of 0.98 in Fig. 9 on the same spectral range as shown in Fig. 12 of the Radziszewski et al. ${ }^{18}$ paper. The agreement between the two studies is very good, which testifies to the strength of the current method in predicting not only the IR absorption frequencies of the tetrapyrroles but also their intensities.

In agreement with Radziszewski et al. ${ }^{18}$, the mode of $\mathrm{H}_{2} \mathrm{P}$, which was observed at $731 \mathrm{~cm}^{-1}$ and attributed to $\mathrm{OPB}$, is predicted at $739.9 \mathrm{~cm}^{-1}$ (scaled by $0.98,725.1 \mathrm{~cm}^{-1}$ ) in the present calculations. However, their comment that this motion will be distributed over several fundamental modes of $\mathrm{D}_{2} \mathrm{P}$ is not borne out by our calculations. As Fig. 10 shows (and listed in Table 3), the N-D OPB mode is well defined and is located at $541.8 \mathrm{~cm}^{-1}$ (scaled by $0.98,530.9 \mathrm{~cm}^{-1}$ ) in a sparse region of the IR spectrum. Moreover, it is actually much stronger than the corresponding $\mathrm{H}_{2} \mathrm{P}$ OPB, so it should be easily identified. While Radziszewski et al. did not present any spectra for this lower frequency region in this early work ${ }^{18}$, they did show a strong band around $540 \mathrm{~cm}^{-1}$ in Fig. 1 for $\mathrm{D}_{2} \mathrm{P}$ in a more recent work. ${ }^{20}$ Confusingly, this band is not listed under the $\mathrm{D}_{2} \mathrm{P}\left(d_{2}\right)$ column in their Table 1 of Ref. 20, but instead a strong band at $540 \mathrm{~cm}^{-1}$ is listed for $\mathrm{H}_{2} \mathrm{P}$ in the $\left(d_{0}\right)$ column. From the actual $\mathrm{H}_{2} \mathrm{P}\left(d_{o}\right)$ and $\mathrm{D}_{2} \mathrm{P}\left(d_{2}\right)$ spectra shown in Fig. 1 of Ref. 20 , we conclude that the $540 \mathrm{~cm}^{-1}$ band is the OPB of $\mathrm{D}_{2} \mathrm{P}$. Contrary to the expectation of Radziszewski et al., ${ }^{18}$ the frequency of this mode is indicative of an ISR value of a "pure" $\mathrm{N}-\mathrm{H}$ vibration. This result is entirely consistent with the results of the current DFT calculations. Clearly, it is not a diluted motion, distributed over many bands as Radziszewski et al. stated in their 1989 paper. ${ }^{18}$

The reason this OPB vibration is not diluted over several modes is evident in Fig. 4. As indicated in that plot, its mass dependence is limited to just two modes, both of which exhibit the inverse dependence on the root of mass. This simple behaviour is entirely attributable to the small number (10) of $b_{3 u}$ symmetry modes listed in Table 1 for the OPB of free-base porphine. Essentially identical behaviour is predicted for TAP, while Fig. 4 predicts the OPB will only be slightly more complex in $\mathrm{H}_{2}$ TBP and $\mathrm{H}_{2} \mathrm{Pc}$ because of the crossing of a single, lower frequency mode.

A key aspect of the current work is the upward shift in the frequencies of specific modes (highlighted in Table 3 ) in the heavier isotopologue upon H/D substitution. As indicated in that table, the most pronounced instance of this effect in free-base porphine is expected in the OPB mode, where the $651.4 \mathrm{~cm}^{-1}$ mode shifts up to $657.9 \mathrm{~cm}^{-1}$. This region is highlighted in Fig. 10 on an expanded intensity scale. This region was presented in the more recent paper by Radziszewski 
Table 6. A comparison of the numerical values arising from the DFT calculations done on the normal modes of $\mathrm{H}_{2} \mathrm{TAP} / \mathrm{D}_{2} \mathrm{TAP}$ with the theoretical values predicted by the product rule for isotope shifts as given by eq. [2].

\begin{tabular}{|c|c|c|c|c|c|}
\hline $\begin{array}{l}\text { Symmetry } \\
\text { (No.) Desc. }\end{array}$ & $\begin{array}{l}\mathrm{D}_{2} \mathrm{TAP} \\
\omega^{\prime}{ }_{1} \ldots \omega_{n}^{\prime}\end{array}$ & $\begin{array}{l}\mathrm{H}_{2} \mathrm{TAP} \\
\omega_{1} \ldots \omega_{n}\end{array}$ & $\begin{array}{l}\text { DFT Freq.Ratios } \\
\omega^{\prime}{ }_{1} \ldots \omega^{\prime}{ }_{n} / \omega_{1} \ldots \omega_{n}\end{array}$ & $\begin{array}{l}\text { Product rule } \\
\text { (eq. [2]) }\end{array}$ & $\Delta=$ \\
\hline$\overline{a_{g}(17) \mathrm{STR}}$ & $1.06216 \mathrm{E}+52$ & $1.50154 \mathrm{E}+52$ & 0.707378629 & 0.707378522 & $1.07126 \mathrm{E}-07$ \\
\hline$b_{1 g}(7) \mathrm{No} H / D \mathrm{dep}$ & $4.89979 \mathrm{E}+18$ & $4.89978 \mathrm{E}+18$ & 1.000000804 & 1 & $8.03673 \mathrm{E}-07$ \\
\hline$b_{2 g}(8) \mathrm{OPB}$ & $1.59631 \mathrm{E}+21$ & $2.25506 \mathrm{E}+21$ & 0.707879423 & 0.707760485 & 0.000118938 \\
\hline$b_{3 g}(16) \mathrm{IPB}$ & $9.26087 \mathrm{E}+47$ & $1.30883 \mathrm{E}+48$ & 0.707570706 & 0.707557622 & 1.30842E-05 \\
\hline$a_{u}(7) \mathrm{No} H / D \mathrm{dep}$ & $5.81598 \mathrm{E}+18$ & $5.81597 \mathrm{E}+18$ & 1.000001708 & 1 & $1.70809 \mathrm{E}-06$ \\
\hline$b_{1 u}$ (16) STR & $1.38722 \mathrm{E}+49$ & $1.95482 \mathrm{E}+49$ & 0.709641213 & 0.709641106 & $1.06391 \mathrm{E}-07$ \\
\hline$b_{2 u}(16)$ IBP & $5.74105 \mathrm{E}+48$ & $8.09008 \mathrm{E}+48$ & 0.70964135 & 0.709641106 & 2.43709E-07 \\
\hline$b_{3 u}(9)$ OPB & $5.8226 \mathrm{E}+22$ & $8.20495 E+22$ & 0.709644992 & 0.709641106 & $3.88552 \mathrm{E}-06$ \\
\hline
\end{tabular}

Note: All the normal modes are given even those $\left(b_{1 g}\right.$ and $a_{u}$ symmetries) where no isotope (H/D) dependence is expected upon substitution of the two inner H-atoms (see Table 1).

Fig. 9. Low-resolution ( $\mathrm{fwhm}=4 \mathrm{~cm}^{-1}$ ) plots of the IR absorption spectra generated by the DFT/B3LYP method for the vibrational modes of $\mathrm{H}_{2} \mathrm{P}$ and $\mathrm{D}_{2} \mathrm{P}$. The spectral range and format has been selected for direct comparison with the matrix-IR absorption data published by Radziszewski et al. ${ }^{18}$ As indicated, the predicted values are scaled by a factor of 0.98 throughout.

Scaled (x0.98) DFT IR spectra Porphine

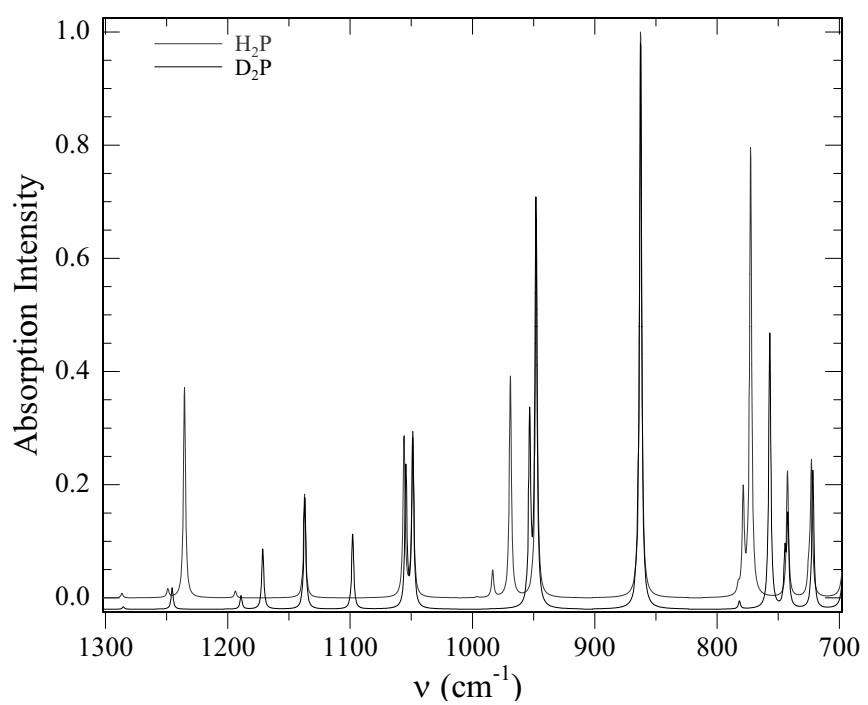

et al. but was not analysed or discussed in the text of the article. ${ }^{20}$ In any case, the ISR effect will not be immediately evident in the recorded spectra, because while the $\mathrm{D}_{2} \mathrm{P}$ mode at $657.9 \mathrm{~cm}^{-1}$ has significant intensity $(4.3 \mathrm{~km} / \mathrm{mol})$, that of the related $\mathrm{H}_{2} \mathrm{P}$ mode at $651.34 \mathrm{~cm}^{-1}$ is very weak $(0.08 \mathrm{~km} / \mathrm{mol})$. In the experimental spectrum of the heavier isotope, this ISR effect will present an "unknown" peak in the spectrum not easily connected with $\mathrm{H}_{2} \mathrm{P}$. However, using the matrix-isolation technique, which has high sensitivity, it should be possible to observe the ISR effect in porphine as already done in phthalocyanine. ${ }^{6}$

\section{Future work on the reverse ISR effect}

While the reverse ISR effect will not be immediately evident in porphine, the situation is much more favourable for its identification in TAP. Figure 11 presents the low-frequency spectral region of interest. Once again the OPB of this mole-
Fig. 10. High-resolution (fwhm $=0.2 \mathrm{~cm}^{-1}$ ) plots of the IR absorption spectra generated by the DFT/B3LYP method for $\mathrm{H}_{2} \mathrm{P}$ and $\mathrm{D}_{2} \mathrm{P}$. The spectral range presented is the region where the large isotope shift on the OPB is predicted. This range was presented in the latest matrix-IR absorption data published by Radziszewski et al. ${ }^{20}$, but the band at $540 \mathrm{~cm}^{-1}$ in the $\mathrm{D}_{2} \mathrm{P}$ spectrum was not attributed to the $\mathrm{OPB}$ mode of $\mathrm{D}_{2} \mathrm{P}$.

Scaled (x0.98) DFT IR spectra Porphine

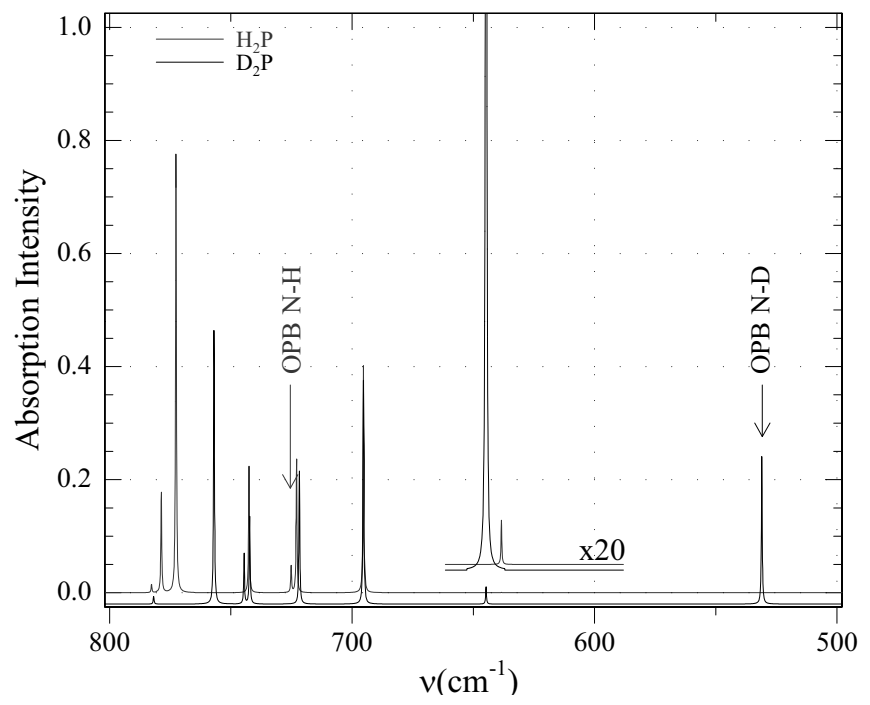

cule shows the expected mass dependence of the N-H OPBs, as indicated by the labelled arrows. Fortuitously, in this case the intensities of the reversed ISR (0.988) modes are of comparable magnitude in the two isotopologues. These two bands are shown with expanded intensities in the centre of Fig. 11. On the basis of the present DFT calculations, TAP is the system of choice for a matrix-isolation study of this reverse ISR effect, because it produces the largest effect, the $\mathrm{H}_{2}$ TAP and $\mathrm{D}_{2}$ TAP modes are equally strong and they occur in a sparse region of the IR spectrum. To the best of our knowledge this study has not yet been attempted.

\section{Conclusions}

The results of the present DFT calculations of H/D substitution on the free-base tetrapyrroles can be summarized as follows. The 
Fig. 11. High-resolution (fwhm $=0.2 \mathrm{~cm}^{-1}$ ) plots of the IR absorption spectra generated by the DFT/B3LYP method for $\mathrm{H}_{2}$ TAP and $\mathrm{D}_{2}$ TAP. The spectra range and format has been selected for examination of the region where the large isotope shift on the OPB mode is predicted to occur.

\section{Scaled (x0.98) DFT IR spectra TAP}

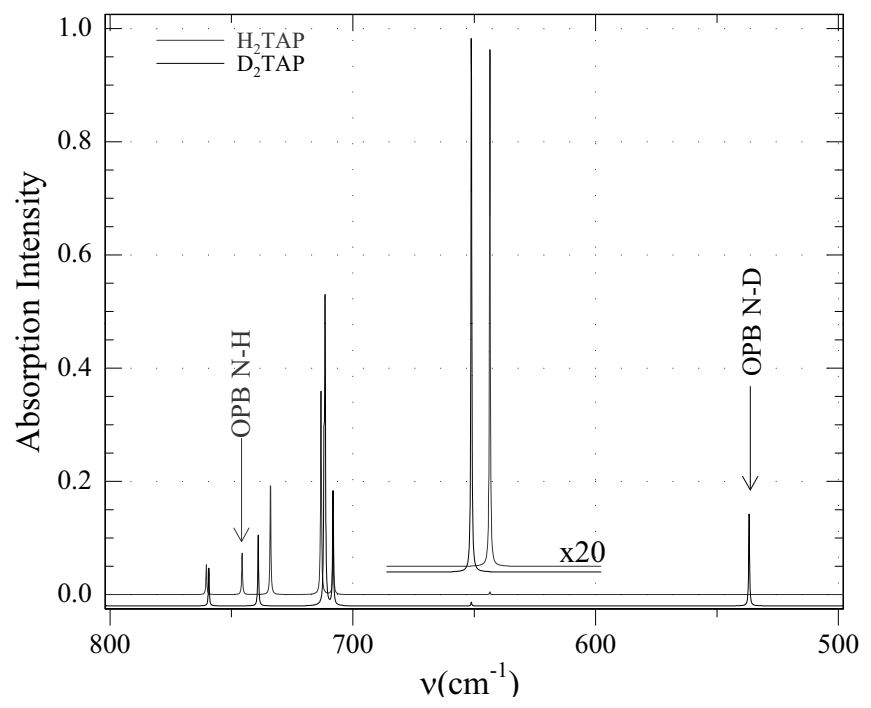

high-frequency, $\mathrm{N}-\mathrm{H}$ bond stretching modes are well localized and direct crossings occur with the $\mathrm{C}-\mathrm{H}$ stretching modes. As these internal modes involve very different motions that are localized on specific bonds, no intermode coupling occurs, yielding the expected values for the isotope shift ratios.

The lower-frequency N-H OPB motions are not distributed over several normal modes principally because the $b_{2 g}$ and $b_{3 u}$ modes are not numerous. As a result, these modes involve well-defined OPB motions in both the $\mathrm{N}-\mathrm{H}$ and the N-D bonds. For the smaller tetrapyrroles (P and TAP) no crossings occur for the $b_{2 g}$ symmetry Raman-active modes. In the larger molecules, crossings occur but the $b_{2 g}$ modes of Pc and TBP still involve localized $\mathrm{N}-\mathrm{H}$ motions, as illustrated by the similarity with the simple mass-dependence curves. Due to a single mode crossing that occurs in both Pc and TBP, frequency increases do occur in the heavier isotopologue, but because of the involvement of only two modes, instances of reversed ISR can be easily identified in the mass-dependent calculations.

The IR-active $b_{3 u}$ OPB modes are slightly more numerous than their $b_{2 g}$ Raman counterparts and exhibit more complex behaviour. For all 4 molecules, the N-H OPB mode is crossed by two modes. Clear differences exist between the crossings of these two modes. One is not (or is only very weakly) coupled with the N-H OP bend and passes directly through, while the other mode is strongly coupled and produces a large avoided crossing. A consequence of the strong coupling in the latter case is that the frequency in the heavier isotopologue increases significantly yielding reversed ISR values.

More complicated behaviour is observed for the $\mathrm{N}-\mathrm{H}$ IPB modes than the OPB modes just described because of the larger number of modes with $b_{2 u}$ and $b_{3 g}$ symmetries. As a result, the $\mathrm{N}-\mathrm{H}$ motions are dispersed over many normal modes. Accordingly, the decrease in the $\mathrm{NH}$ frequencies is much less than the $m_{\mathrm{H}}{ }^{-1 / 2}$ mass dependence due to the dilution of this motion over several modes. No normal mode can be identified as "the" NH or ND IPB mode, since the percentages of $\mathrm{NH}(\mathrm{D})$ motion are always below $30 \%$. Another consequence of this is that most of the modes are nearly parallel, which reduces the extent of modes crossings. Crossings appear in a congested spectral region, where a mode exists involving no NH(D) motion. This is the case in the region $1000 \mathrm{~cm}^{-1}$ in all molecules. In all instances, the crossing is direct and the modes are clearly not strongly coupled. For the $b_{3 g}$ modes couplings occur for some molecules in the high-frequency $\left(1200 \mathrm{~cm}^{-1}\right)$ range but produce only weak avoided crossings. The best examples of this are present in porphine and TBP. This coupling does not occur in TAP and only weakly in Pc.

The $b_{3 u}$ and $b_{2 g}$ OPB modes provide the most clear-cut examples of the effect of avoided crossings. Thus, some of these modes have no effect on each other showing simple, direct crossing without intermode coupling, whereas large avoided crossings are observed in other cases, implying mode frequencies in the same spectral range. Reverse ISR values are obtained in these last cases of large avoided crossings, i.e., crossing between strongly coupled modes involving same atomic motions. This leads to a mixture of these motions, which depend very strongly on minor molecular effects such as the mass of the $\mathrm{H}$ atom on the vibration. In all the situations of reverse ISR effect, the vector diagrams of the atomic motions reveal a reversal of the directions of the N-H and N-D movements between the light and heavy isotopologue, explaining how ISR $<1$ can arise.

Based on predictions made in the present work and the previously identified instance in which an ISR has already been observed in matrix-IR spectra ${ }^{6}$ of the phthalocyanines, it would appear that TAP is the ideal system to make a definitive experimental study of this effect through observation of OPB modes.

\section{Acknowledgement}

This work was supported by the Ulysses France-Ireland research exchange grant 2010-2012 (PHC program Ulysses No. 25709VA).

\section{References}

(1) Braun, J.; Limbach, H.-H.; Williams, P. G.; Morimoto, H.; Wemmer, D. E. J. Am. Chem. Soc. 1996, 118 (30), 7231. doi:10.1021/ja954146n.

(2) Baker, J.; Kozlowski, P. M.; Jarzecki, A. J.; Pulay, P. Theor. Chem. Acc. 1997, 97 (1-4), 59. doi:10.1007/s002140050237.

(3) Mielke, Z.; Sobczyk, L. Vibrational Isotope Effects in Hydrogen Bonds, Chapter 10; In Isotope Effects in Chemistry and Biology; Kohen, A.; Limbach, H.-H., Eds.; CRC Press, Boca Raton, 2006; ISBN 0-8247-2449-6.

(4) An ISR effect of 2.9736, more than two times larger than the $\nu_{\mathrm{H}} / \nu_{\mathrm{D}}$ ISR of 1.41 , would occur in a substitution of muonium (Mu, mass $0.1139775 \mathrm{amu}$ ) by the $\mathrm{H}$ atom (1.0078250 amu), but because of the short lifetime of the former "atom", this is generally not a viable experimental proposal.

(5) Herzberg, G. Molecular Spectra and Molecular Structure: Infrared and Raman of Polyatomic Molecules; Krieger Pub Co., 1991.

(6) Murray, C.; Dozova, N.; McCaffrey, J. G.; FitzGerald, S.; Shafizadeh, N.; Crépin, C. Phys. Chem. Chem. Phys. 2010, 12 (35), 10406. doi:10.1039/c0cp00055h.

(7) Milgrom, L. R. The colours of life. An introduction to the chemistry of porphyrins and related compounds; Oxford University Press, Oxford, 1997; ISBN 019-855380-3. 
(8) Li, X.; Zgierski, M. Z. J. Phys. Chem. 1991, 95 (11), 4268. doi:10.1021/j100164a020.

(9) Wilson, E. B.; Decius, J. C.; Cross, P. C. Molecular Vibrations; McGraw-Hill, New York, 1955, Reprinted, Dover, 1980.

(10) (a) Liu, J.; Zhang, X.; Zhang, Y.; Jiang, J. Spectrochim. Acta [A] 2007, 67 (5), 1232. doi:10.1016/j.saa.2006.10.013; (b) Zhang, X.; Zhang, Y.; Jiang, J. Vib. Spectrosc. 2003, 33 (1-2), 153. doi:10.1016/j.vibspec.2003.08.001.

(11) In our previous vibrational analysis of the phthalocyanines (Ref. 4) the $z$-axis was chosen perpendicular to the plane of the molecules $\mathrm{H}_{2} \mathrm{Pc}$ and $\mathrm{D}_{2} \mathrm{Pc}$. This was done to allow the modes of these $D_{2 h}$ species to be directly correlated with those of $D_{4 h}$, $\mathrm{ZnPc}$. Use, in the present work, of the axes system in which the $z$-axis is aligned with the two $\mathrm{N}-\mathrm{H}$ bonds has the effect of interchanging the 1 and 3 subscripts of the irreducible representations.

(12) Longuet-Higgins, H. C. Proc. R. Soc. Lond. A Math. Phys. Sci. 1975, 344 (1637), 147. doi:10.1098/rspa.1975.0095.

(13) Frisch, M. J.; Trucks, G. W.; Schlegel, H. B.; Scuseria, G. E.; Robb, M. A.; Cheeseman, J. R.; Montgomery, J. A., Jr.; Vreven, T.; Kudin, K. N.; Burant, J. C.; Millam, J. M.; Iyengar, S. S.; Tomasi, J.; Barone, V.; Mennucci, B.; Cossi, M.; Scalmani, G.; Rega, N.; Petersson, G. A.; Nakatsuji, H.; Hada, M.; Ehara, M.; Toyota, K.; Fukuda, R.; Hasegawa, J.; Ishida, M.; Nakajima, T.; Honda, Y.; Kitao, O.; Nakai, H.; Klene, M.; Li, X.; Knox, J. E.; Hratchian, H. P.; Cross, J. B.; Bakken, V.; Adamo, C.; Jaramillo, J.; Gomperts, R.; Stratmann, R. E.; Yazyev, O.; Austin, A. J.; Cammi, R.; Pomelli, C.; Ochterski, J. W.; Ayala, P. Y.; Morokuma, K.; Voth, G. A.; Salvador, P.; Dannenberg, J. J.; Zakrzewski, V. G.; Dapprich, S.; Daniels, A. D.; Strain, M. C.; Farkas, O.; Malick, D. K.; Rabuck, A. D.; Raghavachari, K.; Foresman, J. B.; Ortiz, J. V.; Cui, Q.; Baboul, A. G.; Clifford, S.; Cioslowski, J.; Stefanov, B. B.; Liu, G.; Liashenko, A.; Piskorz, P.; Komaromi, I.; Martin, R. L.; Fox, D. J.; Keith, T.; Al-Laham, M. A.; Peng, C. Y.; Nanayakkara, A.; Challacombe, M.; Gill, P. M. W.; Johnson, B.; Chen, W.; Wong, M. W.; Gonzalez, C.; Pople, J. A. Gaussian 03, Revision E.01; Gaussian Inc., Wallingford, CT, 2004.

(14) Gardner, A. M.; Wright, T. G. J. Chem. Phys. 2011, 135 (11), 114305. doi:10.1063/1.3638266.

(15) Groner, P. Normal coordinate analysis; In Handbook of Vibrational Spectroscopy; Vol. 3; Chalmers, J. M.; Griffiths, P. R.; Wiley, NY.; p. 1992, 2002.

(16) The theoretically predicted $\nu_{\mathrm{H}} / \nu_{\mathrm{D}}$ ratio depends on the reduced mass of the normal mode under consideration. It will be close to, but slightly less than $\sqrt{ } 2$ in the case of a pure $X-H(D)$ vibration, where $\mathrm{X}$ is the mass of the entire molecule minus 1(2). Since the mass of the H-atom is $1.0078250 \mathrm{amu}$ and the D atom is $2.0141018 \mathrm{amu}$, the limiting (with $\mathrm{X}$ of infinite mass) predicted $v_{\mathrm{H}} / v_{\mathrm{D}}$ ratio is $\sqrt{ } 1.9985=1.41367$.

(17) This finding may seem inconsistent with the group theory analysis presented in Table 1, but the additional modes of TBP and $\mathrm{Pc}$ are located at frequencies both above and below the range shown in the figure. The least number of modes are indeed present in the smaller molecules $\mathrm{P}$ and TAP.

(18) Radziszewski, J. G.; Waluk, J.; Michl, J. Chem. Phys. 1989, 136 (2), 165. doi:10.1016/0301-0104(89)80044-8.

(19) Radziszewski, J. G.; Waluk, J.; Nepras, M.; Michl, J. J. Phys. Chem. 1991, 95 (5), 1963. doi:10.1021/j100158a015.
(20) Radziszewski, J. G.; Nepras, M.; Balaji, V.; Waluk, J.; Vogel, E.; Michl, J. J. Phys. Chem. 1995, 99 (39), 14254. doi:10.1021/ j100039a011.

\section{Appendix A}

The values of the numbers $t, r_{x}, r_{y}$, and $r_{z}$ in eq. [2] can be read directly from the character table of the point group, while the exponents $a, b$. . must be determined by group theoretical methods for the atoms concerned. For the $D_{2 h}$ molecule freebase tetraazaporphine $\left(\mathrm{H}_{2} \mathrm{TAP}\right) \mathrm{H} / \mathrm{D}$ substitution will produce the reducible representation $\left(\Gamma_{i H}\right)$ for the motion involving ONLY the two inner $\mathrm{H}$-atoms

$$
\Gamma_{i H}=6 \quad-2 \quad 0 \quad 0000002
$$

which gives $1 a_{g}, 1 b_{2 g}, 1 b_{3 g}, 1 b_{1 u}, 1 b_{2 u}$, and $1 b_{3 u}$. Thus, the value for exponent $a$ is 1 in the case of H/D substitution for all six symmetries. Moreover, as only $\mathrm{H}$-atoms are being substituted, the reduced mass term $\mu_{\alpha}^{\prime} / \mu_{\alpha}$ in eq. [2] becomes $m_{\mathrm{H}} / m_{\mathrm{D}}$.

Substitution of these values in eq. [2] thereby provides the following expressions for the isotopic shifts of the 6 modes affected by substitution of the two inner hydrogen atoms.

$a_{g}[17]$

$$
\frac{\omega_{8}^{\prime} \omega_{17}^{\prime} \ldots \omega_{69}^{\prime} \omega_{72}^{\prime}}{\omega_{8} \omega_{17} \ldots \omega_{69} \omega_{72}}=\left[\left(\frac{m_{\mathrm{H}}}{m_{\mathrm{D}}}\right)^{1}\right]^{1 / 2}
$$

$b_{2 g}[8]:$

$$
\frac{\omega_{5}^{\prime} \omega_{11}^{\prime} \ldots \omega_{31}^{\prime} \omega_{39}^{\prime}}{\omega_{5} \omega_{13} \ldots \omega_{32} \omega_{35}}=\left[\left(\frac{m_{\mathrm{H}}}{m_{\mathrm{D}}}\right)^{1}\left(\frac{I_{\mathrm{Y}}^{\mathrm{D} 2}}{I_{\mathrm{Y}}^{\mathrm{H} 2}}\right)^{1}\right]^{1 / 2}
$$

$b_{3 g}[16]:$

$$
\frac{\omega_{9}^{\prime} \omega_{13}^{\prime} \ldots \omega_{64}^{\prime} \omega_{68}^{\prime}}{\omega_{9} \omega_{12} \ldots \omega_{64} \omega_{68}}=\left[\left(\frac{m_{\mathrm{H}}}{m_{\mathrm{D}}}\right)^{1}\left(\frac{I_{\mathrm{x}}^{\mathrm{D} 2}}{I_{\mathrm{x}}^{\mathrm{H} 2}}\right)^{1}\right]^{1 / 2}
$$

$b_{1 u}[16]:$

$$
\frac{\omega_{14}^{\prime} \omega_{23}^{\prime} \ldots \omega_{66}^{\prime} \omega_{71}^{\prime}}{\omega_{11} \omega_{19} \ldots \omega_{66} \omega_{71}}=\left[\left(\frac{m_{\mathrm{H}}}{m_{\mathrm{D}}}\right)^{1}\left(\frac{M^{\mathrm{D} 2}}{M^{\mathrm{H} 2}}\right)^{1}\right]^{1 / 2}
$$

$b_{2 u}[16]:$

$$
\frac{\omega_{9}^{\prime} \omega_{13}^{\prime} \ldots \omega_{64}^{\prime} \omega_{68}^{\prime}}{\omega_{9} \omega_{12} \ldots \omega_{64} \omega_{68}}=\left[\left(\frac{m_{\mathrm{H}}}{m_{\mathrm{D}}}\right)^{1}\left(\frac{M^{\mathrm{D} 2}}{M^{\mathrm{H} 2}}\right)^{1}\right]^{1 / 2}
$$

$b_{3 u}[9]:$

$$
\frac{\omega_{1}^{\prime} \omega_{3}^{\prime} \ldots \omega_{27}^{\prime} \omega_{33}^{\prime}}{\omega_{1} \omega_{3} \ldots \omega_{26} \omega_{34}}=\left[\left(\frac{m_{\mathrm{H}}}{m_{\mathrm{D}}}\right)^{1}\left(\frac{M^{\mathrm{D} 2}}{M^{\mathrm{H} 2}}\right)^{1}\right]^{1 / 2}
$$

In these equations the mode numbering, $\omega_{n}$, is that generated by the DFT calculation, which also provides the moments of inertia for the two isotopologues. $m_{\mathrm{H}}$ and $m_{\mathrm{D}}$ are the atomic masses of hydrogen and deuterium, respectively, while $M^{\mathrm{D} 2}$ and $M^{\mathrm{H} 2}$ are the molecular masses of $\mathrm{D}_{2}$ TAP and $\mathrm{H}_{2} \mathrm{TAP}$, respectively. The outcome of this analysis is compared with DFT results in Table 6. 